\title{
Processing magnesium and its alloys by high-pressure torsion: an overview
}

\author{
Roberto B. Figueiredo ${ }^{\mathrm{a}}$, Terence G. Langdon ${ }^{\mathrm{b}}$ \\ ${ }^{\mathrm{a} D e p a r t m e n t ~ o f ~ M e t a l l u r g i c a l ~ a n d ~ M a t e r i a l s ~ E n g i n e e r i n g, ~ U n i v e r s i d a d e ~ F e d e r a l ~ d e ~ M i n a s ~ G e r a i s, ~}$ \\ 31270-901 Belo Horizonte, Brazil \\ ${ }^{\mathrm{b}}$ Materials Research Group, Department of Mechanical Engineering, University of Southampton, \\ Southampton SO17 1BJ, UK
}

\begin{abstract}
Magnesium and its alloys have attracted significant attention in recent years because they display high strength-to-density ratios, they are biodegradable and they provide a potential for hydrogen storage. Many investigations have examined the effect of high-pressure torsion processing on the microstructures and properties of these materials so that numerous reports are now available. This overview provides a summary of the observations reported to date on the structure and mechanical property evolution including the nature of grain refinement, the grain boundary misorientation distributions, texture evolution and the minimum grain size. For convenience, the mechanical properties are separated into hardness, tensile behavior and superplastic properties. It is shown that the mechanism of grain refinement differs from other metallic materials processed by severe plastic deformation but high strength may be achieved in magnesium alloys and exceptional ductility in pure magnesium. Hydrogen storage and corrosion behavior are also examined together with a discussion of recent attempts to produce magnesiumbased nanocomposites through processing by high-pressure torsion.
\end{abstract}

Keywords: high-pressure torsion; magnesium; mechanical properties; microstructure; severe plastic deformation.

*corresponding author: figueiredo@demet.ufmg.br 


\section{Introduction}

Magnesium and its alloys have attracted significant attention from the scientific community over the last three or four decades. Specifically, the increasing requirements to reduce weight in the transportation industry and in portable electronic devices has prompted an interest in this metal due to its low density. In addition, magnesium exhibits good biocompatibility and the byproducts of its degradation are not aggressive to the human body so that it is an ideal candidate material for many biodegradable implants. ${ }^{[1,2]}$ Moreover, magnesium can be used also for hydrogen storage which makes it interesting and attractive for a wide range of energy-related applications. ${ }^{[3]}$ The main drawbacks in the practical use of magnesium have centered on combinations of low formability at low temperatures, low strength and relatively rapid corrosion. ${ }^{[4]}$ As a consequence, much research has been devoted to obtaining an understanding of the mechanical behavior of this metal at low temperatures and measuring and interpreting the corrosion behavior and mechanisms. ${ }^{[5]}$ Numerous investigations have focused on alloy development in order to attain improvements in strength, ductility and corrosion while other research has concentrated on evaluating the effects of various processing operations including the use of severe plastic deformation (SPD) techniques.

It is well established that thermo-mechanical processing leads to a significant improvement in the mechanical properties of magnesium and its alloys but the limited formability of this material at low temperatures has necessitated the implementation of high temperature processing. Thus, conventional rolling, extrusion and forging operations are conducted at high temperatures and this limits the effectiveness of any strain hardening mechanisms. Similarly, SPD techniques ${ }^{[6]}$ such as equal-channel angular pressing (ECAP) ${ }^{[7]}$ are conducted at high temperatures and this permits an increase in the dislocation density, a decrease 
in the grain size and a break-up of any second phase particles which thereby affects the mechanical behavior of the metals. Since the effectiveness of SPD techniques is limited at high operating temperatures and there is a consequent need to process magnesium and its alloys by SPD at low temperatures, it is crucial to impose high hydrostatic compressive stresses during the processing operation in order both to prevent cracking and to suppress the occurrence of any segmentation. This may be achieved through the use of the SPD technique of high-pressure torsion (HPT). ${ }^{[8]}$

Processing by HPT provides an SPD procedure in which a sample is subjected to a high applied pressure by compression between massive anvils and then concurrently deformed by shear due to rotation of one of the anvils. The basic principles of the HPT process are illustrated in Figure $1^{[9]}$ and it is possible to use this procedure to achieve the low temperature forming of magnesium with a high strain hardening and exceptional grain refinement to the submicrometer or even the nanometer range. The first investigations on the HPT processing of magnesium were conducted in the early 1990s using a Mg-1.5\% Mn-0.3\% Ce alloy ${ }^{[10,11]}$ and thereafter many investigations were conducted by different groups to investigate the properties of pure $\mathrm{Mg}$ and a wide range of Mg alloys after processing by HPT. The extensive research in this field has led to novel information on the structural evolution and the achievable properties including the mechanisms of plastic deformation at low temperatures and fine grain sizes, the occurrence of improved corrosion behavior and the potential for improving the hydrogen storage properties.

This overview was undertaken with the objective of providing a reasonably comprehensive summary of the main developments in Mg processing by HPT over the past two decades. For convenience, the overview is divided into a series of essentially separate topics including the basic principles of structural evolution, the significance of grain refinement, the 
relevant mechanical properties and the levels of hydrogen storage, corrosion resistance and biocompatibility in the as-processed materials.

\section{Structure evolution}

\subsection{Grain refinement}

The microstructural evolution of metallic materials during SPD processing is now well documented. ${ }^{[6]}$ Thus, dislocations are generated during the early stages of plastic deformation and there is a gradual evolution towards the development of cell boundaries and low-angle grain boundaries (LAGBs) throughout the volume of the material. This continuity of deformation leads to an increase in the average misorientation between grains and to the formation of high-angle grain boundaries (HAGBs). Nevertheless, it is now readily apparent that the mechanism of grain refinement in magnesium and $\mathrm{Mg}$ alloys processed by SPD at high temperatures differs in a significant way from that observed in other metallic materials. It is known that magnesium exhibits dynamic recrystallization which leads to the formation of new grains along the original grain boundaries and these occur in a well-defined necklace pattern. ${ }^{[12-15]}$ Significant grain refinement is observed during high temperature ECAP leading to the possible production of a multi-modal grain size distribution during processing. ${ }^{[16-21]}$

Multi-modal grain size distributions were observed in the early stages of HPT processing of a magnesium alloy at high temperatures ${ }^{[22]}$ and also at low temperatures ${ }^{[23,24]}$ and there is experimental evidence that the mechanism of grain refinement of magnesium subjected to SPD processing at room temperature is similar to that observed at high temperatures. ${ }^{[25]}$ Plastic deformation leads to the formation of new grains along the grain boundaries but, unlike the SPD processing of face-centered cubic metals, dislocation structures and subgrain boundaries are not formed in the interiors of the coarser grains in the early stages of deformation. Nevertheless, the 
continuity of plastic deformation leads to an increase in the volume fraction of refined grains and ultimately to the consumption of the whole volume of the initial coarse-grained structure. Figure 2 shows examples of the grain structures of pure magnesium at different stages of HPT processing at room temperature (RT, $296 \mathrm{~K})$ up to a maximum number, $N$, of 10 turns. ${ }^{[25]}$ Thus, a multi-modal grain size distribution is visible after 1/8 turn with a significant area of coarse grains but the area fraction of refined grains increases at $1 / 2$ rotation and the structure at 10 turns contains a small number of grains larger than $\sim 1 \mu$ m but almost all of the material is then composed of ultrafine grains. This mechanism of grain refinement is similar to the general model of grain refinement proposed for the processing of magnesium by ECAP. ${ }^{[17,20]}$

Transmission electron microscopy (TEM) images of the microstructures of a magnesium AZ31 alloy at different stages of HPT processing are shown in Figure $3 .^{[26]}$ Thus, coarse grains without a dislocation substructure are observed at 1/4 turn and at 1 turn and the fraction of refined grains increases with increasing amounts of imposed strain. Further processing to 5 and 10 turns leads to a complete refinement of the grain structure and this evolution is also confirmed by the inverse pole figures for the AZ31 alloy shown in Figure 4. ${ }^{[27]}$ Images of the structures at the center, mid-radius and periphery of a disc processed to 1 turn of HPT are given in Figures 4a, $4 \mathrm{~b}$ and 4c, respectively, and it is clear that the fraction of fine grains increase with increasing distance from the center of the disk and therefore with increasing torsional strain. By contrast, Figure 4d shows the structure at the periphery of a disc processed to 15 turns and the microstructure is now fully refined.

\subsection{Grain boundary misorientations}

The evolution of grain boundary misorientation with the imposed strain also differs from the behavior generally observed in other metallic materials processed by SPD. Usually there is a 
large fraction of LAGBs at low imposed strains in materials such as aluminum ${ }^{[28,29]}$ and iron ${ }^{\text {[30] }}$ whereas in magnesium a majority of the grain boundaries tend to exhibit high angles at all stages of the processing. Figure 5 shows the distributions of the grain boundary misorientation in pure magnesium processed to $1 / 8,1 / 2$ and 10 turns of HPT at RT. ${ }^{[31]}$ A significant fraction of boundaries with misorientations $<15^{\circ}$ is observed in the material processed to only $1 / 8$ turn although most of the boundaries have larger misorientations. Increasing the imposed strain leads to an increase in the fraction of boundaries with angles of $\sim 30^{\circ}$ of misorientation and this preferential misorientation persists up to a saturation in the structure evolution at 10 turns. Slip propagation across grain boundaries with misorientations lower than $35^{\circ}$ has been reported in fine-grained magnesium. ${ }^{[32]}$ Thus, the high frequency of boundaries with misorientations of $\sim 30^{\circ}$ suggests that this slip transfer mechanism takes place during the HPT processing of magnesium. It is worth noting that a similar evolution, although with fewer low angle boundaries, was observed also in a ZK60 alloy. ${ }^{[33]}$

\subsection{Texture evolution}

Magnesium and its alloys develop a strong texture upon plastic deformation and consequently a significant texture is also observed in samples processed by HPT. Figure 6 shows representative pole figures obtained for pure magnesium processed at different pressures to different levels of shear strain where the orientation system is such that ND corresponds to the normal direction (parallel to the torsion axis) and TD is the tangential direction (parallel to the shear direction). ${ }^{[34]}$ It is apparent that the c-axis aligns close to ND, the overall texture exhibits a steady-state with increasing shear strain and the hydrostatic pressure has only a minor effect on the texture intensity but no influence on the c-axis alignment. 
A similar texture evolution was observed in the magnesium AZ31 alloy. ${ }^{[35,36]}$ Figure 7 shows the pole figures for this material before and after 1 and 5 turns of HPT where the orientation system is such that SD is the shear direction and RD is the radial direction. ${ }^{[35]}$ The asreceived material exhibits an [hki0] fiber and but this changes to a [0001] fiber with the c-axis parallel to the torsion axis after 1 turn of HPT and further processing to 5 turns leads to no significant additional change. A basal texture with a slight rotation towards the shear direction was observed in Mg-1.43\% Nd and Mg-1.44\% Ce alloys processed by HPT. ${ }^{[37]}$

A prompt change in texture upon HPT compression was reported in a ZK60 alloy ${ }^{[38]}$ and a basal fiber texture was observed after only $1 / 8$ turn in pure magnesium. ${ }^{[31]}$ This rapid evolution in texture is attributed to the compressive deformation that is introduced prior to the torsional straining in HPT. It is known that twinning events lead to a preferential orientation in which the c-axis aligns with the compression axis with less than $10 \%$ strain. ${ }^{[39]}$ Also, a basal fiber texture leads to a preferential distribution of grain boundary misorientations around $30^{\circ}{ }^{[40]}$ which agrees with the distributions observed in pure magnesium ${ }^{[31]}$ and a ZK60 alloy ${ }^{[33]}$ processed by HPT.

\section{Mechanical properties}

Processing by SPD usually promotes significant hardening of metallic materials where the increase in strength is attributed to the consequent decrease in grain size and a corresponding increase in the dislocation density. Nevertheless, materials with relatively low melting points

may exhibit softening ${ }^{[41]}$ due to an activation of different deformation mechanisms such as grain boundary sliding at RT and this may introduce significant improvements in ductility. Magnesium alloys exhibit an increase in strength with HPT processing but there are few reports of an associated improved ductility.

\subsection{Hardness evolution}


Measuring the microhardness distribution is a useful and simple way to evaluate the homogeneity of samples processed by SPD. Thus, many investigations have shown a more rapid increase in hardness at the periphery of discs of different metallic materials, including magnesium alloys, and a consequent gradual evolution towards a homogeneous distribution with increasing numbers of rotations. This agrees with the expected distribution of strain which is larger at the edges of the discs. However, early reports showed an inhomogeneity in the distribution of hardness in the through-thickness direction in an AZ31 alloy. ${ }^{[42-44]}$ An inhomogeneity of deformation distribution along the through-thickness direction is attributed to the use of samples having a high sample thickness-to-diameter ratio ${ }^{[45-47]}$ and to differences in the friction coefficient between the upper and lower anvils. ${ }^{[47]}$ Later it was shown that this heterogeneity is not observed in aluminum processed using similar procedures ${ }^{[48,49]}$ and this demonstrates that the tendency for heterogeneity in the hardness distribution is associated specifically with magnesium. A recent report showed that a homogeneity along both the radial direction and the through-thickness direction was achieved in an AZ91 alloy after 10 turns of HPT. ${ }^{[50]}$

Despite the early heterogeneity in the hardness distribution along the through-thickness direction, the hardness evolution of magnesium and its alloys follow a trend with the imposed strain. Thus, plotting hardness as a function of the imposed strain presents an opportunity to evaluate the effect of HPT processing on the strength of these materials. Figure 8 shows plots of hardness as a function of the imposed equivalent strain for pure magnesium ${ }^{[51]}$ and AZ31 ${ }^{[26]}$ and ZK60 ${ }^{[33]}$ alloys. The evolution of hardness in pure magnesium is similar to that observed in high purity aluminum in which there is an initial hardening stage followed by a softening and then saturation. A similar trend was also observed during processing of pure magnesium at a 
cryogenic temperature. ${ }^{[52]}$ This softening in pure magnesium has been attributed to recrystallization ${ }^{[51]}$ and the onset of grain boundary sliding. ${ }^{[25]}$ Commercial magnesium alloys exhibit a typical strain hardening behavior but the saturation is attained at low strains, typically less than 20. The saturation (or maximum) hardness values for different magnesium alloys are summarized in Table 1 with the minimum grain sizes reported. The hardness saturation in commercial alloys are typically in the range of $\sim 110 \sim 130 \mathrm{kgf} / \mathrm{mm}^{2}$ but slightly larger hardness values are observed in alloys with a high content of rare earth elements. ${ }^{[73,75]}$ The evolution of hardness in Mg alloys with a high content of alloying elements may be affected by previous thermal treatments. ${ }^{[75,76]}$ Supersaturated alloys can also exhibit a further increase in hardness due to an ageing treatment post-HPT as observed in the WE43 ${ }^{[64,77]}$, Mg-8\% Gd-3\% Y-0.4\% Zr ${ }^{[71]}$ and Mg-8.2\% Gd-3.8\% Y-1.0\% Zn-0.4\% Zr ${ }^{[72]}$ alloys. It is important to note that much higher hardness values are observed in immiscible $\mathrm{Mg}$ based systems, such as $\mathrm{Mg}-17 \% \mathrm{Ni}-17 \% \mathrm{Pd}$ and Mg-17\% Ni-17\% Sn, subjected to large numbers of turns of HPT. ${ }^{[7]}$

\subsection{Tensile properties}

The increase in strength due to the HPT processing of magnesium alloys usually leads to a brittle behavior in tension but processing at high temperatures can increase the strength and provide limited ductility. For example, a Mg-4.7\% Y-4.6\% Gd-0.3\% Zr alloy exhibited yield and ultimate stresses of $\sim 450 \mathrm{MPa}$ and $475 \mathrm{MPa}$, respectively, with an elongation of $2.5 \%$ when processed at $200{ }^{\circ} \mathrm{C}{ }^{[73]}$ and a WE43 alloy exhibited a yield strength of over $300 \mathrm{MPa}$ with an elongation of $\sim 1 \%$ when processed in the range of $200-300{ }^{\circ} \mathrm{C} \cdot{ }^{[77]}$ Also, a short annealing after HPT processing may increase the ductility. For example, an increase in strength and a remarkably uniform elongation of 20.5\% was reported in a ZKX600 alloy processed by HPT and 
subjected to a 1 min annealing treatment at $300{ }^{\circ} \mathrm{C}^{[63]}$ and an increase in elongation was reported also in a ZK60 alloy processed by HPT and annealed for $20 \mathrm{~min}$ at $200{ }^{\circ} \mathrm{C} .{ }^{[78]}$

Pure magnesium processed by HPT exhibits a different behavior in tension compared to magnesium alloys because it shows an increase in strength compared to its coarse-grained counterpart together with a remarkable ductility. Figure 9 shows the appearance of specimens of pure magnesium processed by 10 turns of HPT and pulled to failure at room temperature at different strain rates, where elongations larger than 300\% are observed at the lowest strain rates. ${ }^{[25]}$ Reports of high elongations in pure magnesium processed by HPT are also available. ${ }^{[51,79]}$ The deformation mechanism operating in fine-grained pure magnesium at RT was investigated and the results show that grain boundary sliding plays a key role in accommodating the plastic strain. ${ }^{[25,80]}$

\subsection{Superplasticity}

Superplasticity denotes the very high elongations which may be achieved in many metals when testing in tension at elevated temperatures. Recent reports ${ }^{[81,82]}$ documented a formal definition of superplasticity as the ability of a material to exhibit an elongation of at least $400 \%$ with a strain rate sensitivity of $\sim 0.5$. It is now accepted that superplasticity is observed in finegrained metals deformed at high temperatures under conditions such that grain boundary sliding is the rate controlling mechanism. ${ }^{[83]}$ Thus, the grain refinement introduced by HPT provides the opportunity for developing superplasticity in magnesium alloys if the grain size remains reasonably stable at high temperatures.

The stability of the grain structure was evaluated in an AZ31 alloy processed by HPT and subjected to annealing at different temperatures. ${ }^{[84]}$ Thus, it was observed that there is a drop in the hardness at $423 \mathrm{~K}$ indicating recrystallization but the average grain size of $\sim 2 \mu \mathrm{m}$ remains 
sufficiently fine for the advent of superplasticity. Annealing at temperatures up to $673 \mathrm{~K}$ leads to an increase in grain size but all of the measured grain sizes were smaller than $10 \mu \mathrm{m}$ which is generally considered the typical threshold for superplasticity. ${ }^{[85]}$

High temperature shear punch testing was used to evaluate the deformation mechanism in Mg-9\% Gd-4\% Y-0.4\% Zr (GW94) ${ }^{[86]}$ and Mg-5\% Gd-4\% Y-0.4\% Zr ${ }^{[70]}$ alloys processed by HPT. The results showed a peak strain rate sensitivity of $\sim 0.5$ at $623 \mathrm{~K}$ and an activation energy in the range of $\sim 100 \sim 110 \mathrm{~kJ} \cdot \mathrm{mol}^{-1}$ which is consistent with grain boundary sliding ${ }^{[87]}$ as the ratecontrolling mechanism.

Superplastic elongations were reported in several different magnesium alloys processed by HPT. Figure 10 shows the appearance of specimens of a $\mathrm{Mg}-9 \% \mathrm{Al}$ alloy processed by 5 turns of $\mathrm{HPT}$ at $423 \mathrm{~K}$ and pulled in tension at $473 \mathrm{~K}$ at different strain rates, where the elongations over $400 \%$ confirm the occurrence of superplasticity. ${ }^{[65]}$ A maximum strain-rate sensitivity of $\sim 0.52$ and elongations over $1000 \%$ were also reported in an AZ91 alloy. ${ }^{[88]}$

In practice, the grain sizes achieved with HPT processing are sufficiently small that grain boundary sliding contributes to the plastic deformation at temperatures which are lower than generally anticipated and this contributes significantly to improving the overall ductility of magnesium and its alloys. Typically, grain boundary sliding contributes to plastic flow at temperatures above $\sim 0.5 T_{\mathrm{m}}$ where $T_{\mathrm{m}}$ is the absolute melting point of the material. However, a comprehensive investigation showed that grain boundary sliding contributed to the deformation of pure magnesium even at room temperature. ${ }^{[25]}$ Thus, superplastic elongations were reported at temperatures as low as $323 \mathrm{~K}$ in a Mg-8\% Li alloy processed by 5 turns of HPT ${ }^{[66]}$ and a very recent report gave evidence for a strain-rate sensitivity of 0.37 and superplasticity at RT ( 0.35 $T_{\mathrm{m}}$ ) in a Mg-8\% Li alloy with increasing numbers of turns of HPT up to a maximum of 200. ${ }^{[89]}$ 
Figure 11 shows the stress vs strain curves for this alloy processed by extrusion without SPD, by 5 turns of HPT and by 200 turns of HPT together with the appearance of the tensile specimens after failure. ${ }^{[89]}$ There is a very clear change in the shape of the curve after HPT processing to a very large number of turns and the elongation of $>400 \%$ confirms the advent of true superplasticity. A summary of all reports of superplasticity in magnesium alloys processed by HPT is provided in Table 2.

\section{Hydrogen storage}

Magnesium forms a hydride in an atmosphere containing a high level of hydrogen and this effect can be utilized to store energy provided it is feasible to control the absorption and desorption rates. It is desirable in practice that these rates are fast at low temperatures and the material has a capability of withstanding multiple cycles of storage. However, pure magnesium needs to be heated in order to achieve appropriate rates of absorption and desorption. The crystalline defects introduced by SPD processing can enhance the diffusion rate in metallic materials and therefore processing by HPT has the potential of improving the performance of magnesium-based materials for hydrogen storage. Figure 13 shows the evolution of the mass content of hydrogen in pure magnesium as a function of time during exposure at $423 \mathrm{~K}$ to an atmosphere with $3 \mathrm{MPa}$ of hydrogen pressure for samples both before and after HPT processing. ${ }^{[51]}$ The annealed material and the material subjected to only one quarter of a turn of HPT in Figure 12 exhibit very low storage capacities up to $100,000 \mathrm{~s}$ whereas the sample processed to 10 turns of HPT shows much faster and larger amounts of storage. This improved performance is attributed to the HPT-induced defects that enhance the diffusion rate.

Further studies demonstrated that alloying elements stabilize the defects introduced during HPT processing such that a ZK60 alloy exhibited an improved hydrogen storage 
performance at high numbers of cycles. ${ }^{[90]}$ Processing by HPT was used also to compact magnesium-based powders with the overall objective of improving the hydrogen storage performance. For example, pure magnesium powders compacted by HPT exhibited a better performance which was attributed to the formation of a Mg-MgO composite in which the dispersion of oxides prevents or inhibits grain growth. ${ }^{[91]}$ The addition of other metallic powders can also influence the hydrogen storage performance. Thus, it was shown that the addition of $2 \%$ of Ni powders improves the kinetics ${ }^{[91]}$, magnesium hydrides and iron powders were mixed and then compacted by HPT to produce pronounced grain refinement and good hydrogen sorption properties ${ }^{[92]}$ and the hydrogen storage performance was also evaluated in Mg and Ni powders processed by HPT. ${ }^{[93-95]}$

Recent reports ${ }^{[96-99]}$ have shown that processing by large numbers of HPT turns can be used to mix different elements to magnesium at the atomic scale and thereby to tailor the hydrogen storage performance of the processed material. For example, a Mg4NiPd alloy was designed and fabricated by melting high purity pieces of the metals and processing by 1500 rotations of HPT under a pressure of 6 GPa where this alloy exhibited a b.c.c. structure with the capacity to store hydrogen at room temperature. ${ }^{[92]}$ Room temperature hydrogen absorption and release was also reported in $\mathrm{Mg}-50 \% \mathrm{Zr}^{[96]}$ and $\mathrm{MgVCr}{ }^{[99]}$ alloys subjected to large strains in HPT.

\section{Corrosion and biocompatibility}

Magnesium and its alloys usually exhibit poor resistance against corrosion since the oxide layers formed on the surfaces of these materials are porous and they are unable to prevent further corrosion in different environments. ${ }^{[101]}$ Nevertheless, magnesium is considered part of a special group of biocompatible materials that undergoes degradation in a biological 
environment. ${ }^{[102]} \mathrm{A}$ recent report demonstrated that processing by severe plastic deformation, including HPT, does not affect the cytotoxicity of pure magnesium. Figure 13 shows the metabolic activity of SAOS-2 cells after 24 hours exposure to samples of magnesium in the ascast condition and after rolling, rolling and annealing, rolling and ECAP and after HPT processing. ${ }^{[103]}$ The activity in all conditions tested is $90 \%$ or larger compared to the control group (not exposed to magnesium) which reveals high levels of cell viability. Thus, magnesium has the potential for use as a bio-degradable material which is absorbed by the body after application but in practice the rate of degradation of magnesium in biological environments is too fast and this leads to the formation of hydrogen gas bubbles around implants. Accordingly, controlling the degradation is of great importance for making use of this material in aggressive environments or as an implant material.

A recent report compared the corrosion behavior of pure magnesium after different processing methods, including as-cast, rolling, rolling and annealing, and processing by ECAP and HPT, and the results showed that the SPD techniques of ECAP and HPT can enhance the corrosion resistance. ${ }^{[103]}$ Figure 14 shows Nyquist curves obtained in a $\mathrm{NaCl}$ solution and it is readily apparent that the materials processed by rolling plus ECAP or by HPT exhibit larger arcs which suggest an increased resistance against corrosion. ${ }^{[103]}$ Also, the experiments showed a transition from a localized corrosion in the as-cast material to a homogeneous corrosion in the material processed by HPT. By contrast, some other recent experiments, also on pure magnesium, suggested there was no significant improvement in the corrosion resistance through HPT processing. ${ }^{[104]}$ Finally, it is important to note that the use of pure magnesium as an implant material has the advantage of avoiding alloying elements and HPT processing is an effective way for controlling the degradation mechanism. 
There is evidence that processing by HPT may also improve the corrosion resistance in magnesium alloys. A transition from pitting to homogeneous corrosion was reported in a Mg-2\% Zn- $0.24 \%$ Ca alloy and this change in behavior was attributed to homogenization in the precipitate distributions during HPT. ${ }^{[105,106]}$ The degradation rate was evaluated in a similar alloy using hydrogen evolution tests and the results are shown in Figure 15 for an alloy tested in a simulated body fluid. ${ }^{[107]}$ Thus, a decrease in the degradation rate with increasing numbers of HPT turns is observed in the material processed from the as-cast condition or after a solution treatment (ST). A recent report showed also that annealing the HPT-processed alloy may improve even further the corrosion resistance. ${ }^{[108]}$

\section{Fabrication of composites}

The use of high-pressure torsion to mix and compact metallic powders or chips has recently attracted significant attention since it provides an opportunity for mixing different materials to produce metal matrix composites. For example, it was shown that pure magnesium powders produced by arc plasma evaporation can be consolidated by HPT and the fine surface layer of $\mathrm{MgO}$ on the powders becomes a homogeneous dispersion of $\mathrm{MgO}$ particles within the composite. ${ }^{[109]}$ Figure 16 shows TEM images of the powders and the HPT-consolidated composite. As noted earlier, the consolidation of magnesium-based powders has been used extensively to produce samples with improved hydrogen storage performance. ${ }^{[1-98]}$

Magnesium-based nanocomposites may be produced also by using HPT processing with discs of different materials. ${ }^{[110-114]}$ Thus, discs of a magnesium ZK60 alloy were placed between two discs of an aluminum 1050 alloy and processed by HPT where Figure 17a shows the appearance of the processed material after 1 and 5 turns and details of the structures at the center and at the edge of the disc processed by 5 turns are given in Figures 17b and c, respectively. 
Later, it was reported that increasing the number of turns to 20 led to a significant increase in hardness at the edge of the composite to values that were larger than those observed in bulk aluminum or in bulk magnesium alloys. ${ }^{[113]}$ Using only two discs, it was shown also that a thin layer of $\mathrm{Mg}_{17} \mathrm{Al}_{12}$ intermetallic was detected on the interface between discs of pure aluminum and pure magnesium processed for up to 20 turns of HPT. ${ }^{[115]}$

\section{Summary and conclusions}

1. High-pressure torsion may be used to process magnesium at low temperatures producing significant grain refinement and hardening. The mechanism of grain refinement at room temperature is similar to that observed at high temperatures in which new grains are formed along the original grain boundaries in a necklace-like fashion and the volume fraction of the fine grains increases with deformation. Grain sizes in the range of hundreds of nanometers are obtained in pure magnesium and in the range of tens of nanometers in alloys with high alloying content.

2. Processing by HPT leads to an increase in strength by grain refinement and strain hardening with many magnesium alloys exhibiting hardness values larger than $90 \mathrm{Hv}$. The processed alloys exhibit brittle behavior in tension which may be alleviated by rapid annealing or by high temperature HPT processing. Pure magnesium exhibits an increase in strength and an exceptional ductility after processing by HPT.

3. Processing by HPT also introduces exceptional superplastic properties in magnesium alloys, improves their hydrogen storage performance and generally, but not always, appears to improve their corrosion resistance. 


\section{Acknowledgements}

RBF acknowledges support from CNPq (grant \#400407/2016-7), FAPEMIG (grant \# APQ-00580-15) and Serrapilheira Institute (grant number Serra-1709-17750). TGL was supported by the European Research Council under Grant Agreement No. 267464SPDMETALS. 


\section{References:}

[1] Y. Chen, Z. Xu, C. Smith, J. Sankar, Acta Biomater., 2014, 10, 4561.

[2] Y. F. Zheng, X. N. Gu, F. Witte, Mater. Sci. Eng. R, 2014, 77, 1.

[3] B. Sakintuna, F. Lamari-Darkrim, M. Hirscher, Int. J. Hydrogen Energy, 2007, 32, 1121.

[4] B. L. Mordike, T. Ebert, Mater. Sci. Eng. A, 2001, 302, 37.

[5] A. Atrens, G. L. Song, M. Liu, Z. M. Shi, F. Y. Cao, M. S. Dargusch, Adv. Eng. Mater., 2015, 17, 400.

[6] R. Z. Valiev, R. K. Islamgaliev, I. V. Alexandrov, Prog. Mater. Sci., 2000, 45, 103.

[7] R. Z. Valiev, T. G. Langdon, Prog. Mater. Sci., 2006, 51, 881.

[8] A. P. Zhilyaev, T. G. Langdon, Prog. Mater. Sci., 2008, 53, 893.

[9] R. B. Figueiredo, G. C. V. De Faria, P. R. Cetlin, T. G. Langdon, J. Mater. Sci., 2013, 48, 4524.

[10] R. Z. Abdulov, R. Z. Valiev, N. A. Krasilnikov, J. Mater. Sci. Let, 1990, 9, 1445.

[11] R. Z. Valiev, N. A. Krasilnikov, N. K. Tsenev, Mater. Sci. Eng. A, 1991, 137, 35.

[12] S. E. Ion, F. J. Humphreys, S. H. White, Acta Metall., 1982, 30, 1909.

[13] A. Galiyev, R. Kaibyshev, G. Gottstein, Acta Mater., 2001, 49, 1199.

[14] M. M. Myshlyaev, H. J. McQueen, A. Mwembela, E. Konopleva, Mater. Sci. Eng. A, 2002, 337, 121.

[15] A. G. Beer, M. R. Barnett, Mater. Sci. Eng. A, 2006, 423, 292.

[16] R. B. Figueiredo, T. G. Langdon, J. Mater. Sci., 2009, 44, 4758.

[17] R. B. Figueiredo, T. G. Langdon, Mater. Trans., 2009, 50, 111.

[18] R. B. Figueiredo, T. G. Langdon, Int. J. Mater. Res. , 2009, 100, 1638.

[19] R. B. Figueiredo, T. G. Langdon, Mater. Sci. Eng. A, 2009, 501, 105. 
[20] R. B. Figueiredo, T. G. Langdon, J. Mater. Sci., 2010, 45, 4827.

[21] R. B. Figueiredo, T. G. Langdon, J. Mater. Sci., 2010, 45, 4827.

[22] P. Serre, R. B. Figueiredo, N. Gao, T. G. Langdon, Mater. Sci. Eng. A, 2011, 528, 3601.

[23] Y. Huang, R. B. Figueiredo, T. G. Langdon, Rev. Adv. Mater. Sci., 2012, 31, 129.

[24] C. L. P. Silva, I. C. Tristão, S. Sabbaghianrad, S. A. Torbati-Sarraf, R. B. Figueiredo, T. G. Langdon, Mater. Res., 2017, 20, 2.

[25] R. B. Figueiredo, S. Sabbaghianrad, A. Giwa, J. R. Greer, T. G. Langdon, Acta Mater., 2017, 122, 322.

[26] J. Xu, X. W. Wang, M. Shirooyeh, G. N. Xing, D. B. Shan, B. Guo, T. G. Langdon, J. Mater. Sci., 2015, 50, 7424.

[27] J. Straska, M. Janecek, J. Gubicza, T. Krajnak, E. Y. Yoon, H. S. Kim, Mater. Sci. Eng. A, 2015, 625, 98.

[28] Y. Ito, Z. Horita, Mater. Sci. Eng. A, 2009, 503, 32.

[29] C. Xu, Z. Horita, T. G. Langdon, Mater. Trans., 2010, 51, 2.

[30] Y. Ivanisenko, R. Z. Valiev, H. J. Fecht, Mater. Sci. Eng. A, 2005, 390, 159.

[31] R. B. Figueiredo, S. Sabbaghianrad, T. G. Langdon, IOP Conf. Series: Mater. Sci. Eng., 2017, 194, 012039.

[32] C. M. Cepeda-Jimenez, J. M. Molina-Aldareguia, M. T. Perez-Prado, Acta Mater., 2015, 88, 232.

[33] S. A. Torbati-Sarraf, S. Sabbaghianrad, R. B. Figueiredo, T. G. Langdon, J. Alloys Compd., 2017, 712, 185.

[34] B. J. Bonarski, E. Schafler, B. Mingler, W. Skrotzki, B. Mikulowski, M. J. Zehetbauer, J. Mater. Sci., 2008, 43, 7513. 
[35] Y. Huang, R. B. Figueiredo, T. Baudin, A. L. Helbert, F. Brisset, T. G. Langdon, J. Mater. Sci., 2012, 47, 7796.

[36] Y. Huang, R. B. Figueiredo, T. Baudin, A. L. Helbert, F. Brisset, T. G. Langdon, Mater. Res., 2013, 16, 577.

[37] Y. I. Bourezg, H. Azzeddine, T. Baudin, A.-L. Helbert, Y. Huang, D. Bradai, T. G. Langdon, Mater. Sci. Eng. A, 2018, 724, 477.

[38] H. J. Lee, S. K. Lee, K. H. Jung, G. A. Lee, B. Ahn, M. Kawasaki, T. G. Langdon, Mater. Sci. Eng. A, 2015, 630, 90.

[39] N. Dixit, K. Y. Xie, K. J. Hemker, K. T. Ramesh, Acta Mater., 2015, 87, 56.

[40] J. A. del Valle, M. T. Perez-Prado, O. A. Ruano, Revista De Metalurgia, 2002, 38, 353.

[41] M. Kawasaki, R. B. Figueiredo, Y. Huang, T. G. Langdon, J. Mater. Sci., 2014, 49, 6586.

[42] R. B. Figueiredo, M. T. P. Aguilar, P. R. Cetlin, T. G. Langdon, Metall. Mater. Trans. A, 2011, 42A, 3013.

[43] R. B. Figueiredo, T. G. Langdon, Mater. Sci. Eng. A, 2011, 528, 4500.

[44] R. B. Figueiredo, T. G. Langdon, Mater. Sci. Forum. 2011. 667-669, 247.

[45] G. Sakai, K. Nakamura, Z. Horita, T. G. Langdon, Mater. Sci. Eng. A, 2005, 406, 268.

[46] A. Hohenwarter, A. Bachmaier, B. Gludovatz, S. Scheriau, R. Pippan, Int. J. Mater. Res. , 2009, 100, 1653.

[47] R. B. Figueiredo, M. T. P. Aguilar, P. R. Cetlin, T. G. Langdon, J. Mater. Sci., 2012, 47, 7807.

[48] M. Kawasaki, R. B. Figueiredo, T. G. Langdon, Acta Mater., 2011, 59, 308.

[49] M. Kawasaki, R. B. Figueiredo, T. G. Langdon, J. Mater. Sci., 2012, 47, 7719. 
[50] A. S. J. Al-Zubaydi, A. P. Zhilyaev, S. C. Wang, P. Kucita, P. A. S. Reed, J. Mater. Sci., 2016, 51, 3380.

[51] K. Edalati, A. Yamamoto, Z. Horita, T. Ishihara, Scripta Mater., 2011, 64, 880.

[52] K. Edalati, J. M. Cubero-Sesin, A. Alhamidi, I. F. Mohamed, Z. Horita, Mater. Sci. Eng. A, 2014, 613, 103.

[53] X. G. Qiao, Y. W. Zhao, W. M. Gan, Y. Chen, M. Y. Zheng, K. Wu, N. Gao, M. J. Starink, Mater. Sci. Eng. A, 2014, 619, 95.

[54] L. R. C. Malheiros, R. B. Figueiredo, T. G. Langdon, Mater. Sci. Forum, 2014. 783-786, 2617.

[55] Y. Huang, R. B. Figueiredo, T. Baudin, F. Brisset, T. G. Langdon, Adv. Eng. Mater., 2012, 14, 1018.

[56] Y. Harai, M. Kai, K. Kaneko, Z. Horita, T. G. Langdon, Mater. Trans., 2008, 49, 76.

[57] S. A. Alsubaie, P. Bazarnik, M. Lewandowska, Y. Huang, T. G. Langdon, J. Mater. Res. Technol., 2016, 5, 152.

[58] D. Arpacay, S. B. Yi, M. Janeček, A. Bakkaloglu, L. Wagner, Mater. Sci. Forum, 2008, 584-586, 6.

[59] A. Al-Zubaydi, R. B. Figueiredo, Y. Huang, T. G. Langdon, J. Mat. Sci., 2013, 48, 4661.

[60] K. Bryła, J. Morgiel, M. Faryna, K. Edalati, Z. Horita, Mater. Let., 2018, 212, 323.

[61] H. J. Lee, B. Ahn, M. Kawasaki, T. G. Langdon, J. Mater. Res. Technol., 2015, 4, 18.

[62] S. A. Torbati-Sarraf, T. G. Langdon, J. Alloys Compd., 2014, 613, 357.

[63] R. X. Zheng, T. Bhattacharjee, A. Shibata, T. Sasaki, K. Hono, M. Joshi, N. Tsuji, Scripta Mater., 2017, 131, 1. 
[64] E. A. Lukyanova, N. S. Martynenko, I. Shakhoya, A. N. Belyakov, L. L. Rokhlin, S. V. Dobatkin, Y. Z. Estrin, Mater. Let., 2016, 170, 5.

[65] M. Kai, Z. Horita, T. G. Langdon, Mater. Sci. Eng. A, 2008, 488, 117.

[66] H. Matsunoshita, K. Edalati, M. Furui, Z. Horita, Mater. Sci. Eng. A, 2015, 640, 443.

[67] F. Q. Meng, J. M. Rosalie, A. Singh, H. Somekawa, K. Tsuchiya, Scripta Mater., 2014, 78-79, 57.

[68] P. Jenei, J. Gubicza, E. Y. Yoon, H. S. Kim, J. Alloys Compd., 2012, 539, 32.

[69] O. B. Kulyasova, R. K. Islamgaliev, Y. H. Zhao, R. Z. Valiev, Adv. Eng. Mater., 2015, $17,1738$.

[70] R. Alizadeh, R. Mahmudi, P. H. R. Pereira, Y. Huang, T. G. Langdon, Mater. Sci. Eng. A, 2017, 682, 577.

[71] L. Tang, Y. Zhao, R. K. Islamgaliev, R. Z. Valiev, Y. T. Zhu, J. Alloys Compd., 2017, 721, 577.

[72] W. T. Sun, X. G. Qiao, M. Y. Zheng, C. Xu, S. Kamado, X. J. Zhao, H. W. Chen, N. Gao, M. J. Starink, Acta Mater., 2018, 151, 260.

[73] S. V. Dobatkin, L. L. Rokhlin, E. A. Lukyanova, M. Y. Murashkin, T. V. Dobatkina, N. Y. Tabachkova, Mater. Sci. Eng. A, 2016, 667, 217.

[74] K. Edalati, R. Uehiro, K. Fujiwara, Y. Ikeda, H.-W. Li, X. Sauvage, R. Z. Valiev, E. Akiba, I. Tanaka, Z. Horita, Mater. Sci. Eng. A, 2017, 701, 158.

[75] W. T. Sun, X. G. Qiao, M. Y. Zheng, Y. He, N. Hu, C. Xu, N. Gao, M. J. Starink, Mater. Sci. Eng. A, 2018, 728, 115.

[76] W. T. Sun, X. G. Qiao, M. Y. Zheng, C. Xu, N. Gao, M. J. Starink, Mater. Des., 2017, 135, 366. 
[77] E. A. Lukyanova, N. S. Martynenko, V. N. Serebryany, A. N. Belyakov, L. L. Rokhlin, S. V. Dobatkin, Y. Z. Estrin, Russian Metallurgy (Metally), 2017, 2017, 912.

[78] S. A. Torbati-Sarraf, S. Sabbaghianrad, T. G. Langdon, Adv. Eng. Mater., 2018, 20, 1700703.

[79] M. Joshi, Y. Fukuta, S. Gao, N. Park, D. Terada, N. Tsuji, IOP Conf. Series: Mater. Sci. Eng., 2014, 63, 012074.

[80] H. Somekawa, T. Mukai, Metall. Mater. Trans. A, 2015, 46A, 894.

[81] M. Kawasaki, R. B. Figueiredo, T. G. Langdon, Adv. Eng. Mater., 2016, 18, 127.

[82] T. G. Langdon, J. Mater. Sci., 2009, 44, 5998.

[83] T. G. Langdon, Mater. Sci. Eng. A, 1994, 174, 225.

[84] L. R. C. Malheiros, R. B. Figueiredo, T. G. Langdon, J. Mater. Res. Technol., 2015, 4, 14.

[85] T. G. Langdon, Metall. Trans. A, 1982, 13A, 689.

[86] R. Alizadeh, R. Mahmudi, A. H. W. Ngan, Y. Huang, T. G. Langdon, Mater. Sci. Eng. A, 2016, 651, 786.

[87] T. G. Langdon, Acta Metall. Mater., 1994, 42, 2437.

[88] A. S. J. Al-Zubaydi, A. P. Zhilyaev, S. C. Wang, P. A. S. Reed, Mater. Sci. Eng. A, 2015, 637, 1.

[89] K. Edalati, T. Masuda, M. Arita, M. Furui, X. Sauvage, Z. Horita, R. Z. Valiev, Scientific Reports, 2017, 7, 2662.

[90] A. Grill, J. Horky, A. Panigrahi, G. Krexner, M. Zehetbauer, Int. J. Hydrogen Energy, 2015, 40, 17144. 
[91] T. Grosdidier, J. J. Fundenberger, J. X. Zou, Y. C. Pan, X. Q. Zeng, Int. J. Hydrogen Energy, 2015, 40, 16985.

[92] D. R. Leiva, A. M. Jorge, T. T. Ishikawa, J. Huot, D. Fruchart, S. Miraglia, C. S. Kiminami, W. J. Botta, Adv. Eng. Mater., 2010, 12, 786.

[93] M. Gajdics, M. Calizzi, L. Pasquini, E. Schafler, A. Revesz, Int. J. Hydrogen Energy, 2016, 41, 9803.

[94] Y. Kusadome, K. Ikeda, Y. Nakamori, S. Orimo, Z. Horita, Scripta Mater., 2007, 57, 751.

[95] Á. Révész, Z. Kánya, T. Verebélyi, P. J. Szabó, A. P. Zhilyaev, T. Spassov, J. Alloys Compd., 2010, 504, 83.

[96] K. Edalati, H. Emami, Y. Ikeda, H. Iwaoka, I. Tanaka, E. Akiba, Z. Horita, Acta Mater., 2016, 108, 293.

[97] K. Edalati, H. Emami, A. Staykov, D. J. Smith, E. Akiba, Z. Horita, Acta Mater., 2015, 99, 150.

[98] H. Emami, K. Edalati, A. Staykov, T. Hongo, H. Iwaoka, Z. Horita, E. Akiba, RSC Advances, 2016, 6, 11665.

[99] K. Fujiwara, R. Uehiro, K. Edalati, H.-W. Li, R. Floriano, E. Akiba, Z. Horita, Mater. Trans., 2018, 59, 741.

[100] K. Edalati, R. Uehiro, Y. Ikeda, H.-W. Li, H. Emami, Y. Filinchuk, M. Arita, X. Sauvage, I. Tanaka, E. Akiba, Z. Horita, Acta Mater., 2018, 149, 88.

[101] G. Song, A. Atrens, Adv. Eng. Mater., 2003, 5, 837.

[102] Q. Chen, G. A. Thouas, Mater. Sci. Eng. R, 2015, 87, 1. 
[103] C. L. P. Silva, A. C. Oliveira, C. G. F. Costa, R. B. Figueiredo, M. de Fátima Leite, M. M. Pereira, V. F. C. Lins, T. G. Langdon, J. Mater. Sci., 2017, 52, 5992.

[104] D. Ahmadkhaniha, Y. Huang, M. Jaskari, A. Järvenpää, M.H. Sohi, C. Zanella, L.P. Karjalainen, T.G. Langdon, J. Mater. Sci., 2018, doi.org/10.1007/s10853-018-2779-1.

[105] J. H. Gao, S. K. Guan, Z. W. Ren, Y. F. Sun, S. J. Zhu, B. Wang, Mater. Let., 2011, 65, 691.

[106] C. Z. Zhang, S. J. Zhu, L. G. Wang, R. M. Guo, G. C. Yue, S. K. Guan, Mater. Des., 2016, 96, 54.

[107] C. Z. Zhang, S. K. Guan, L. G. Wang, S. J. Zhu, J. Wang, R. M. Guo, Adv. Eng. Mater., 2017, 19, 1600326.

[108] C. Z. Zhang, S. K. Guan, L. G. Wang, S. J. Zhu, L. Chang, J. Mater. Res., 2017, 32, 1061.

[109] J. X. Zou, C. F. Pérez-Brokate, R. Arruffat, B. Bolle, J. J. Fundenberger, X. Q. Zeng, T. Grosdidier, W. J. Ding, Mater. Sci. Eng. B, 2014, 183, 1.

[110] B. Ahn, A.P. Zhilyaev, H.J. Lee, M. Kawasaki, T.G. Langdon, Mater. Sci. Eng. A, 2015, 635, 109.

[111] B. Ahn, H.J. Lee, I.C. Choi, M. Kawasaki, J.I. Jang, T.G. Langdon, Adv. Eng. Mater., 2016, 18, 1001.

[112] M. Kawasaki, B. Ahn, H. Lee, A. P. Zhilyaev, T. G. Langdon, J. Mater. Res., 2016, 31, 88.

[113] J. K. Han, H. J. Lee, J. I. Jang, M. Kawasaki, T. G. Langdon, Mater. Sci. Eng. A, 2017, 684, 318. 
[114] M. Kawasaki, J.K. Han, D.H. Lee, J.I. Jang, T.G. Langdon, Adv. Eng. Mater., 2018, DOI: $10.1557 / j m r .2018 .205$

[115] X. G. Qiao, X. Li, X. Y. Zhang, Y. Chen, M. Y. Zheng, I. S. Golovin, N. Gao, M. J. Starink, Mater. Let., 2016, 181, 187. 
Tables:

Table 1 - Summary of the minimum grain sizes, $d$, and saturation hardness reported after HPT processing of different magnesium alloys. The nominal pressure, $P$, and the number of turns, $N$, for HPT processing are also shown.

\begin{tabular}{|c|c|c|c|c|c|}
\hline Alloy & $\mathrm{P}(\mathrm{GPa})$ & $\mathrm{N}$ & $d(\mathrm{~nm})$ & $\begin{array}{l}\text { Hardness } \\
\left(\mathrm{kgf} / \mathrm{mm}^{2}\right)\end{array}$ & Reference \\
\hline Pure Mg & 2 & - & $1000 \sim 5000$ & - & [34] \\
\hline Pure Mg & 6 & 10 & 1000 & 35 & [51] \\
\hline Pure Mg & 6 & 8 & 600 & 55 & [53] \\
\hline Pure Mg & 6 & 10 & 320 & & [25] \\
\hline Pure Mg & 6 & 20 & 1460 & 45 & [54] \\
\hline Pure Mg & 6 & 10 & & $55 \sim 60$ & [24] \\
\hline AZ31 & 6 & 20 & 200 & 120 & [54] \\
\hline AZ31 & 6 & 5 & $900 \sim 1200$ & 105 & [55] \\
\hline AZ31 & 6 & 10 & 110 & 125 & [26] \\
\hline AZ31 & 2.5 & 15 & $150 \sim 200$ & 115 & [27] \\
\hline AZ61 & 3 & 5 & 110 & & {$[56]$} \\
\hline AZ80 & 6 & 10 & 200 & 120 & [57] \\
\hline AZ80 & 3 & 15 & 100 & 125 & [58] \\
\hline AZ91 & 3 & 5 & & 125 & [59] \\
\hline AZ91 & 6 & 20 & & 131 & [54] \\
\hline AZ91 & 6 & 10 & 35 & 135 & [50] \\
\hline EZ33A & 6 & 10 & 130 & 96 & {$[60]$} \\
\hline ZK60 & 6 & 7 & & 123 & [54] \\
\hline ZK60 & 6 & 5 & & 110 & [61] \\
\hline ZK60 & 2 & 5 & 1000 & 124 & [62] \\
\hline ZK60 & 6 & 5 & & 110 & [38] \\
\hline ZK60 & 2 & 5 & 700 & 125 & [33] \\
\hline ZKX600 & 6 & 5 & 100 & 120 & [63] \\
\hline WE43 & 6 & 10 & $30 \sim 50$ & 120 & [64] \\
\hline Mg-9\% Al & 3 & 5 & 150 & 120 & [65] \\
\hline Mg-8\% Li & 3 & 5 & 500 & 63 & [66] \\
\hline Mg-1.44\% Ce & 6 & 10 & & 65 & [37] \\
\hline Mg- $1.43 \% \mathrm{Nd}$ & 6 & 10 & & 96 & [37] \\
\hline Mg-3.4\% Zn & 5 & 20 & 140 & 128 & [67] \\
\hline Mg-4.3\% Zn-0.7\% Y & 2.5 & 10 & 150 & 130 & [68] \\
\hline Mg-1\% Zn-0.13\% Ca & 6 & 5 & 150 & 100 & [69] \\
\hline Mg-5\% Gd-4\% Y-0.4\% Zr & 6 & 8 & 72 & & [70] \\
\hline Mg-8\% Gd-3\% Y-0.4\% Zr & 6 & 10 & 80 & 126 & [71] \\
\hline Mg-8.2\% Gd-3.8\% Y-1.0\% Zn-0.4\% Zr & 6 & 10 & 48 & 126 & [72] \\
\hline Mg-4.71\% Y-4.58\% Gd-0.31\% Zr & 6 & 10 & $20 \sim 30$ & 140 & {$[73]$} \\
\hline Mg-17\% Ni -17\% Pd & 6 & 1500 & 10 & 330 & [74] \\
\hline
\end{tabular}


Table 2 - Summary of testing conditions (temperature, $T$, and strain rate, $\dot{\varepsilon}$,) and maximum elongation for superplasticity in magnesium processed by HPT.

\begin{tabular}{|c|c|c|c|c|c|}
\hline \multirow[t]{2}{*}{ Alloy } & \multirow[t]{2}{*}{ HPT turns } & \multicolumn{2}{|c|}{ Testing conditions } & \multirow{2}{*}{$\begin{array}{c}\text { Maximum } \\
\text { Elongation } \\
(\%)\end{array}$} & \multirow[t]{2}{*}{ Reference } \\
\hline & & $T(\mathrm{~K})$ & $\dot{\varepsilon}\left(\mathrm{s}^{-1}\right)$ & & \\
\hline AZ61 & 5 & 473 & $3.3 \times 10^{-3}$ & 620 & [56] \\
\hline AZ91 & $1-10$ & $423-573$ & $10^{-4}-10^{-2}$ & 1308 & [88] \\
\hline ZK60 & 5 & 473 & $10^{-4}-10^{-3}$ & 535 & [62] \\
\hline Mg-9\% Al & 5 & 473 & $5 \times 10^{-4}-5 \times 10^{-3}$ & 810 & [65] \\
\hline $\mathrm{Mg}-8 \% \mathrm{Li}$ & 5 & $323-473$ & $1 \times 10^{-3}$ & 1330 & [66] \\
\hline Mg-8\% Li & 200 & 300 & $1 \times 10^{-3}$ & 440 & [89] \\
\hline
\end{tabular}


Figures:

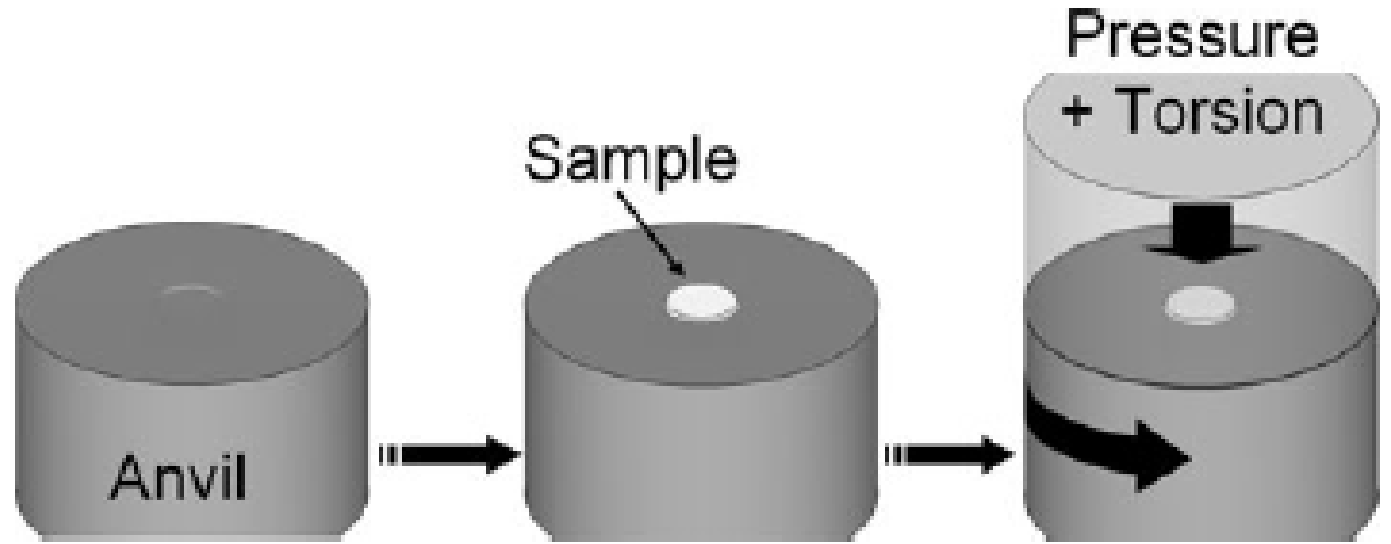

Figure 1 - Illustration of the HPT process. Reproduced with permission. ${ }^{[9]}$ Copyright 2012, Springer Nature. 


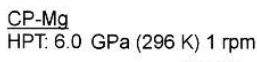
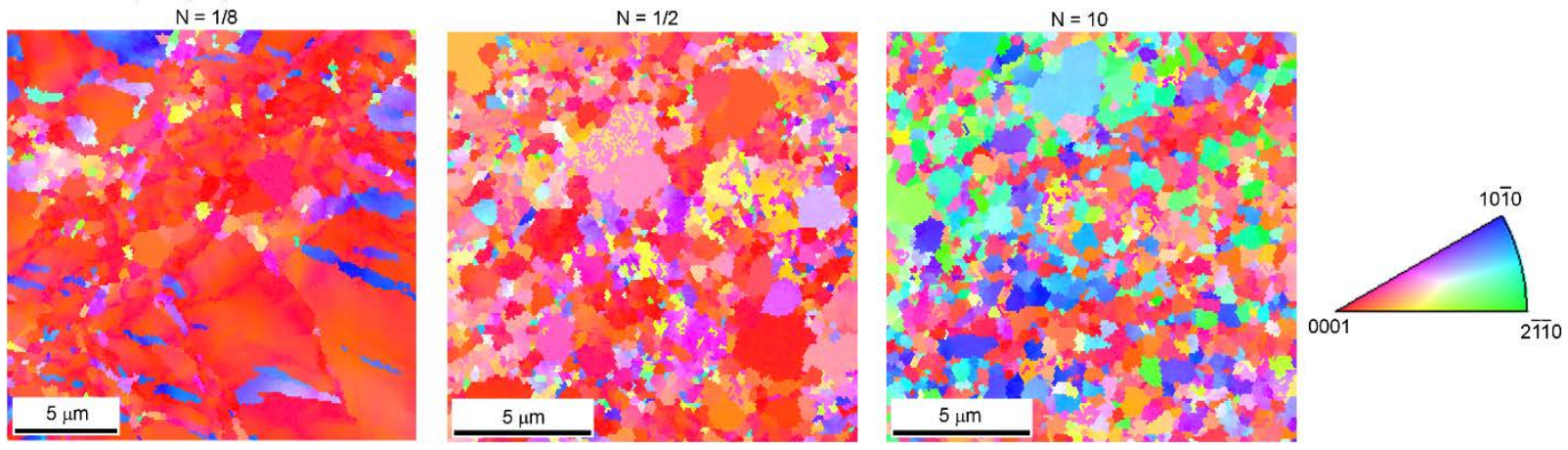

Figure 2 - Evolution of microstructure of Mg during HPT. Reproduced with permission. ${ }^{[25]}$ Copyright 2017, Elsevier. 

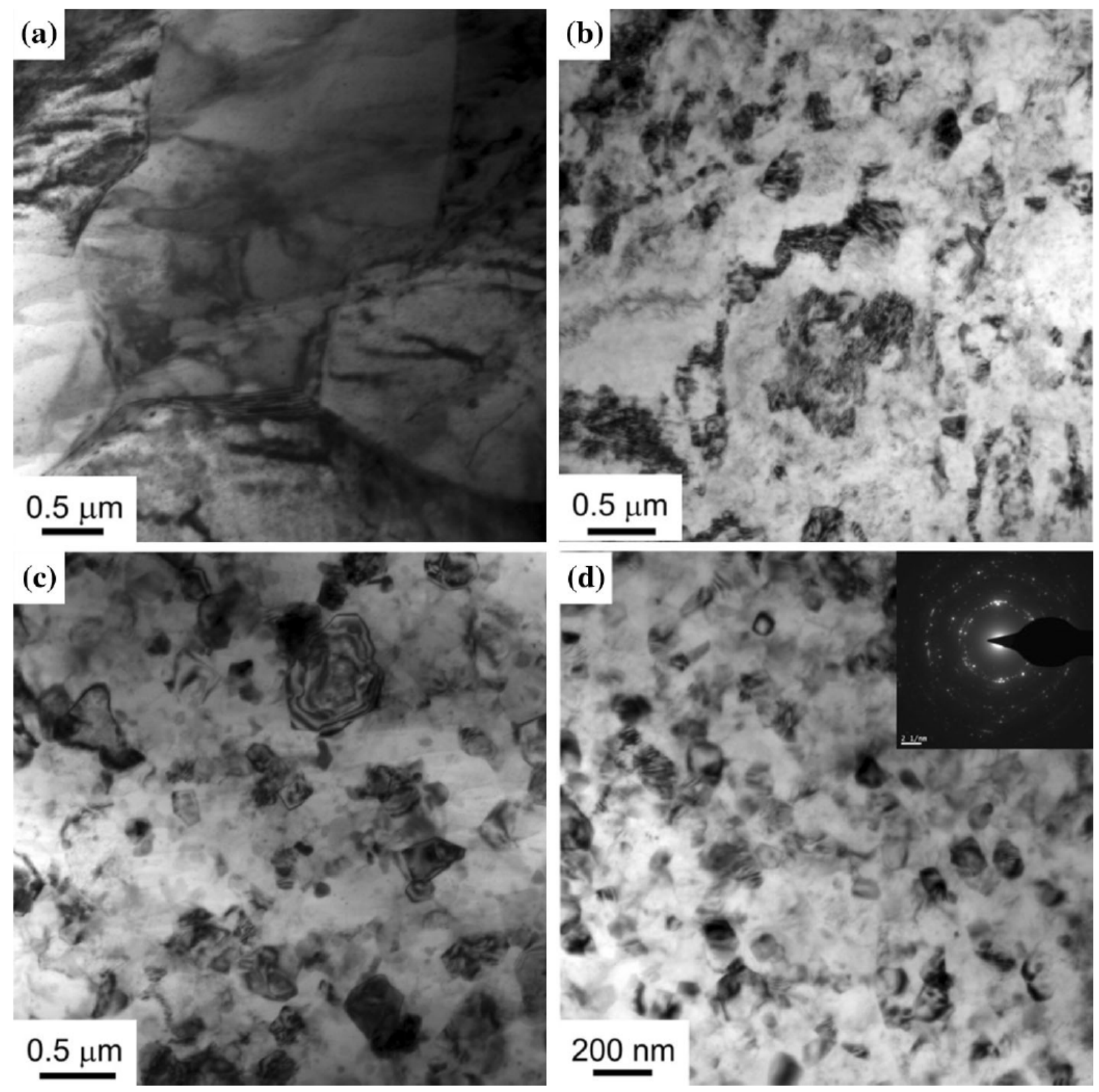

Figure 3 - Evolution of microstructure of an AZ31 alloy processed by HPT to (a) 1/4, (b) 1, (c) 5 and (d) 10 turns of HPT. Reproduced with permission. ${ }^{[26]}$ Copyright 2015, Springer Nature. 

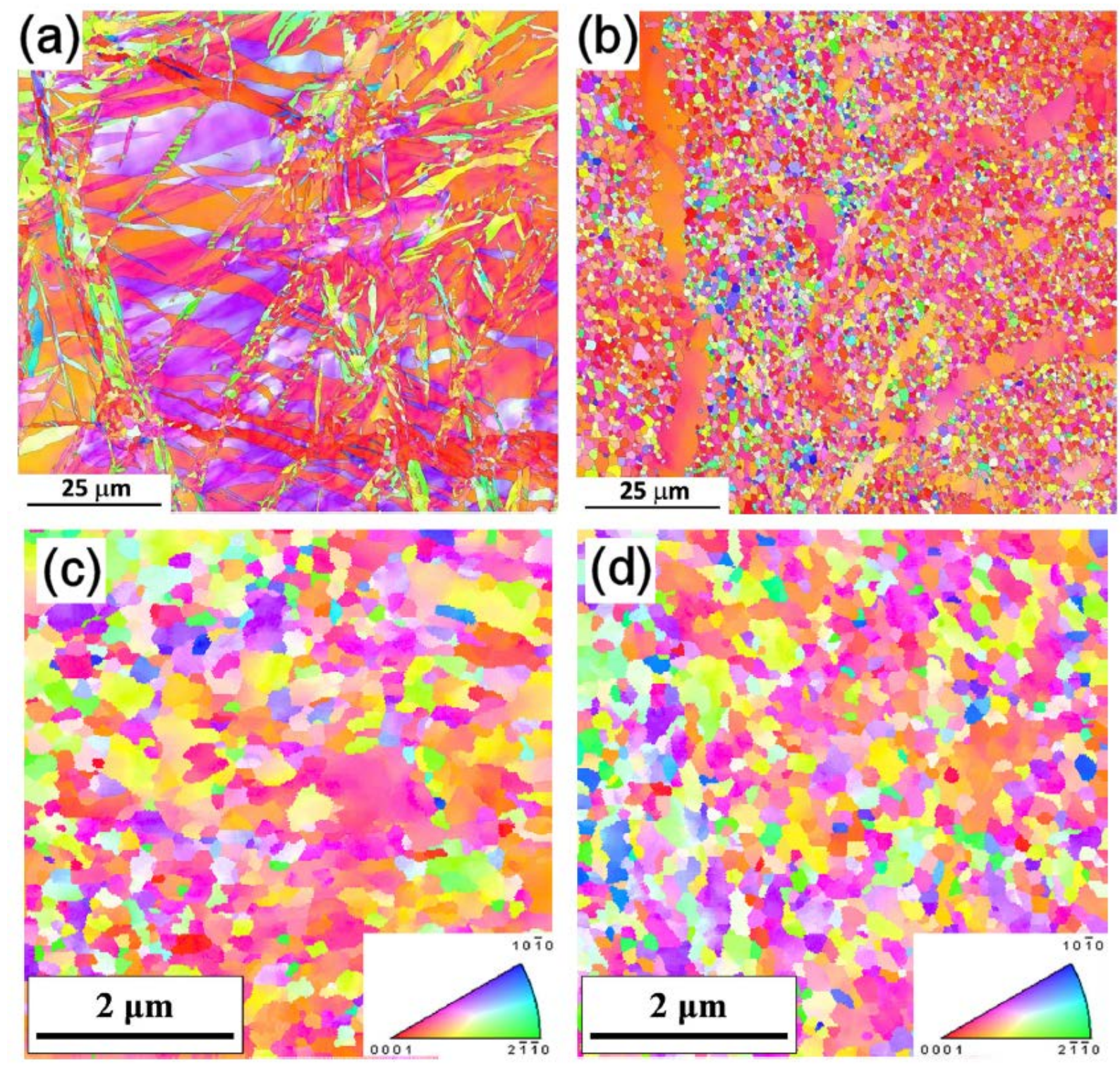

Figure 4 - Microstructure of an AZ31 alloy processed by HPT to (a,b,c) 1 turn and to (d) 15 turns observed using EBSD (a,b) and automated crystallographic orientation mapping in TEM (c,d). The images were made at the center (a), the mid-radius (b) and the periphery (c,d) of the discs. Reproduced with permission. ${ }^{[27]}$ Copyright 2015, Elsevier. 


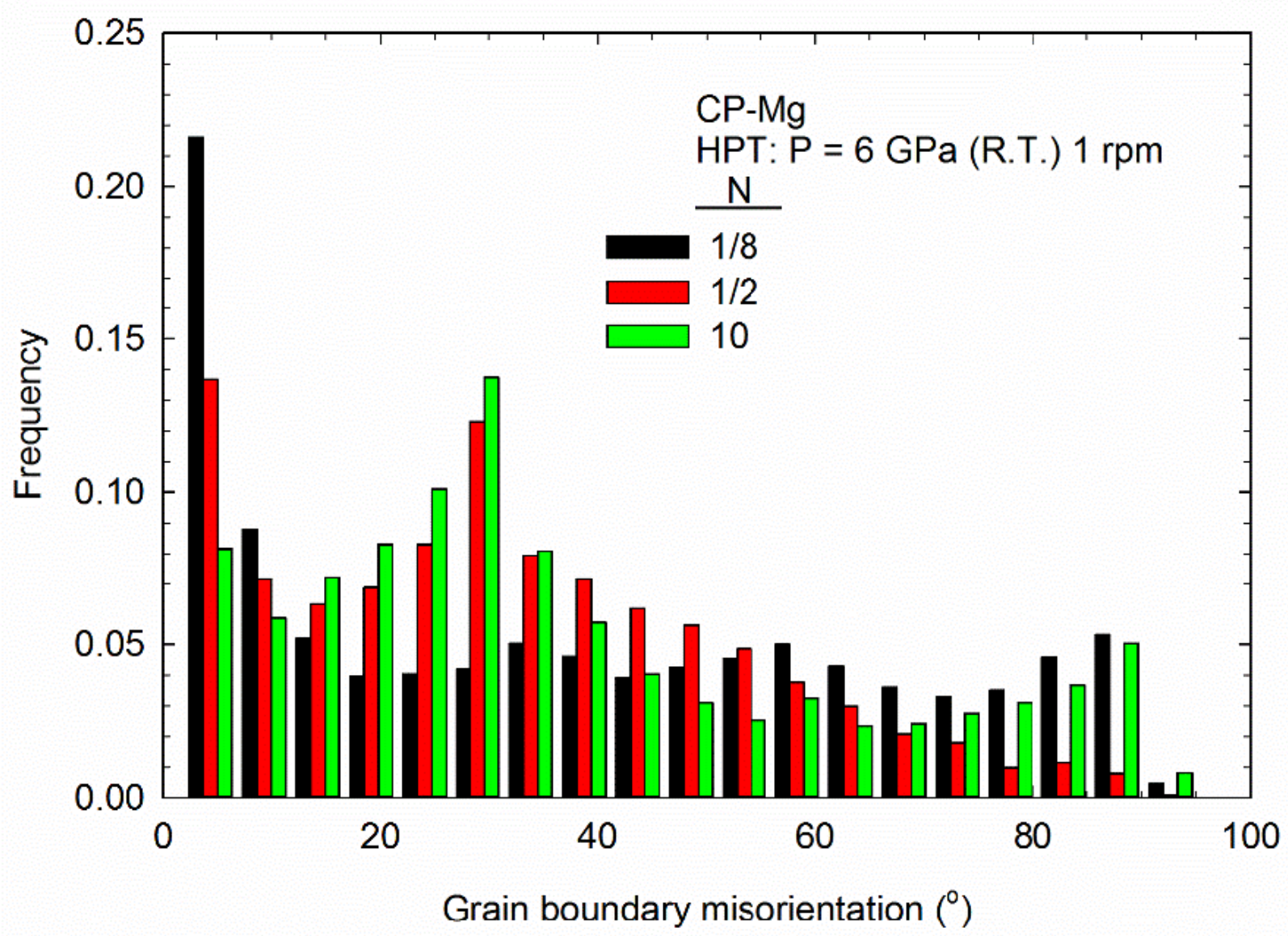

Figure 5 - Distribution of grain boundary misorientation in pure magnesium at different imposed strain. Reproduced under CC-BY license. ${ }^{[31]}$ Copyright 2017, IOP Publishing Limited. 

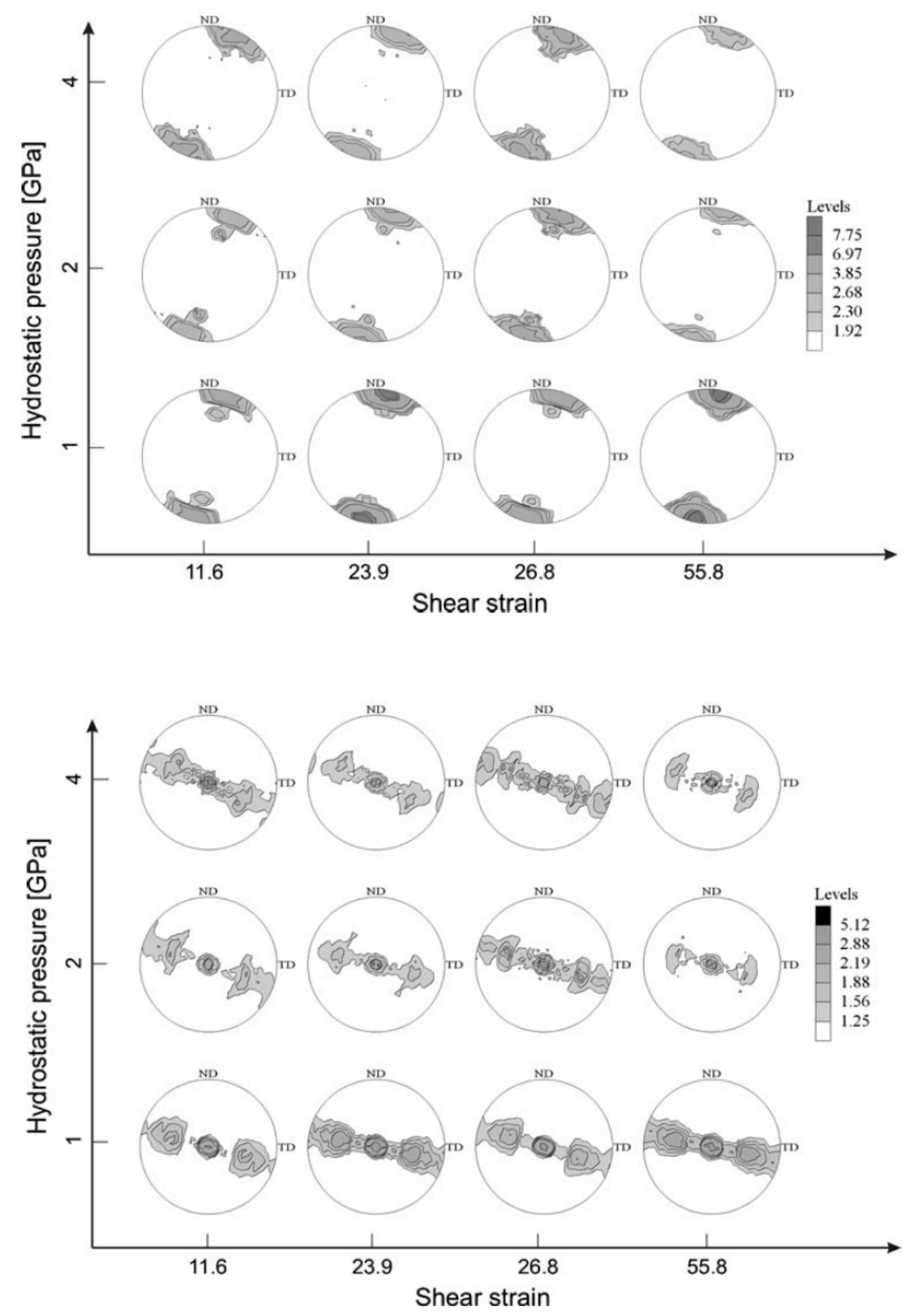

Figure 6 - Texture evolution in pure $\mathrm{Mg}$ as a function of the hydrostatic pressure and shear strain imposed during HPT represented by (a) (0002) and (b) (10-10) pole figures. Reproduced with permission. ${ }^{\text {[3] }}$ Copyright 2008, Springer Nature. 
[0001]
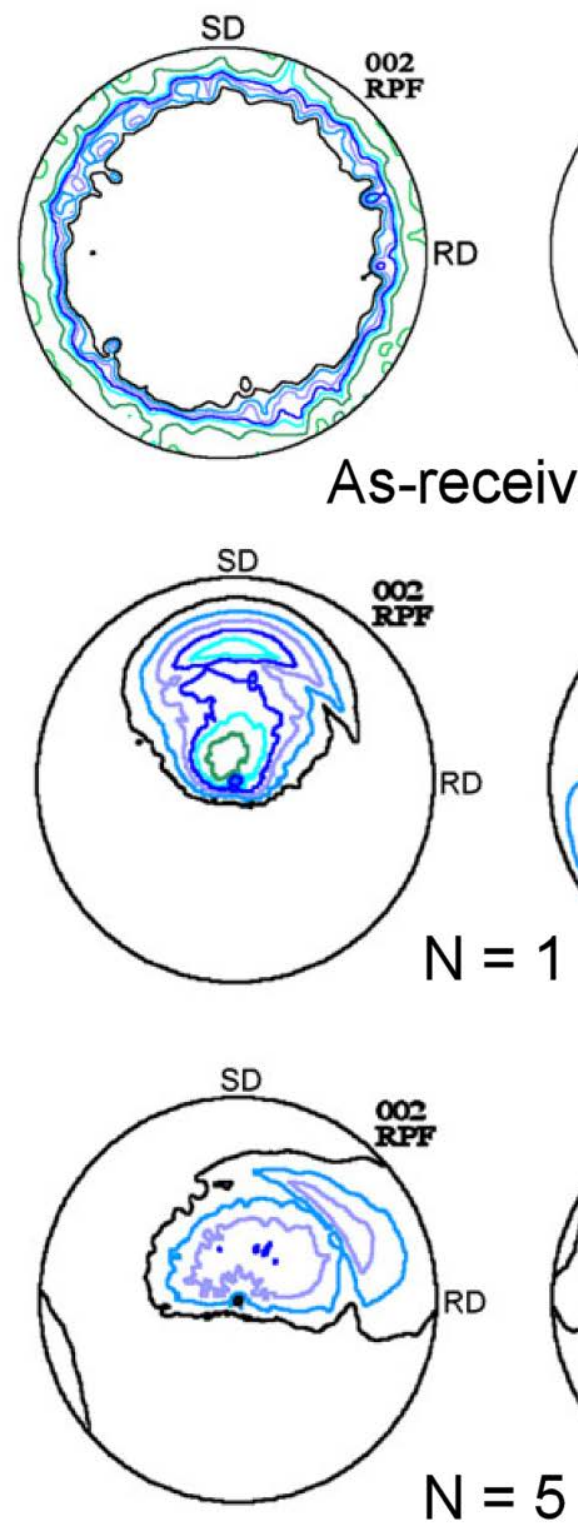

[10̄̄o]

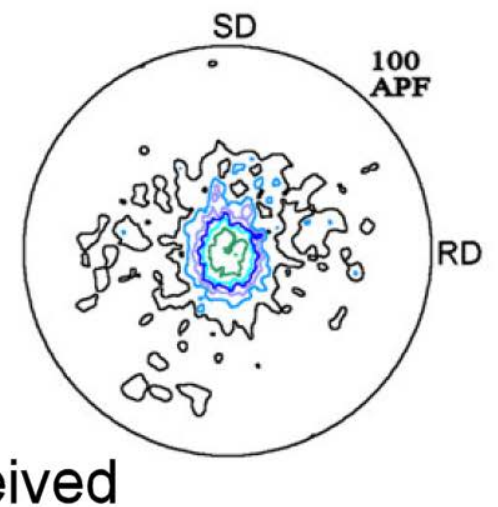

14.0

12.0

10.0

8.0

6.0

4.0

3.0

2.5

2.0

1.5

1.0

Figure 7 - Pole figures determined in an AZ31 alloy in the as-received condition and after processing by HPT to 1 and 5 turns. The pole figures are plotted on the plane defined by the shear direction (SD) and radial direction (RD). Reproduced with permission. ${ }^{[35]}$ Copyright 2012, Springer Nature. 

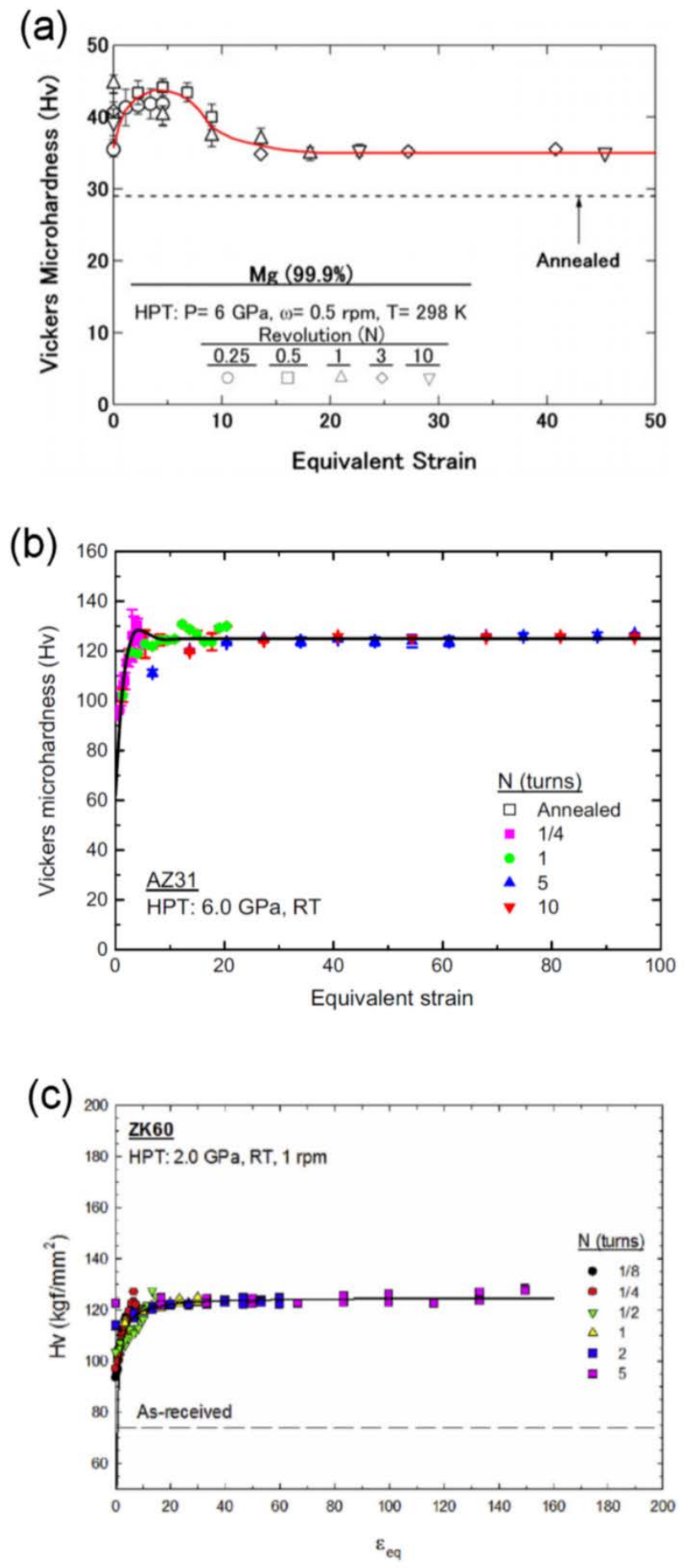

Figure 8 - Vickers microhardness plotted as a function of the equivalent strain in (a) pure magnesium (reproduced with permission. ${ }^{[51]}$ Copyright 2011, Elsevier) and (b) AZ31 (reproduced with permission. ${ }^{\text {[26] }}$ Copyright 2015 Springer Nature.) and (c) ZK60 (reproduced with permission. ${ }^{[33]}$ Copyright 2017, Elsevier) alloys. 
CP-Mg

HPT: $6.0 \mathrm{GPa}(296 \mathrm{~K}) \mathrm{N}=10$

Tensile test: $T=296 \mathrm{~K}$

Strain rate $\left(\mathrm{s}^{-1}\right)$

Untested

\section{Elongation (\%)}

20

70

130

310

360

Figure 9 - Appearance of tensile specimens of pure magnesium processed by 10 turns of HPT and pulled to failure at room temperature at different strain rates. Reproduced with permission. ${ }^{[25]}$ Copyright 2017, Elsevier. 


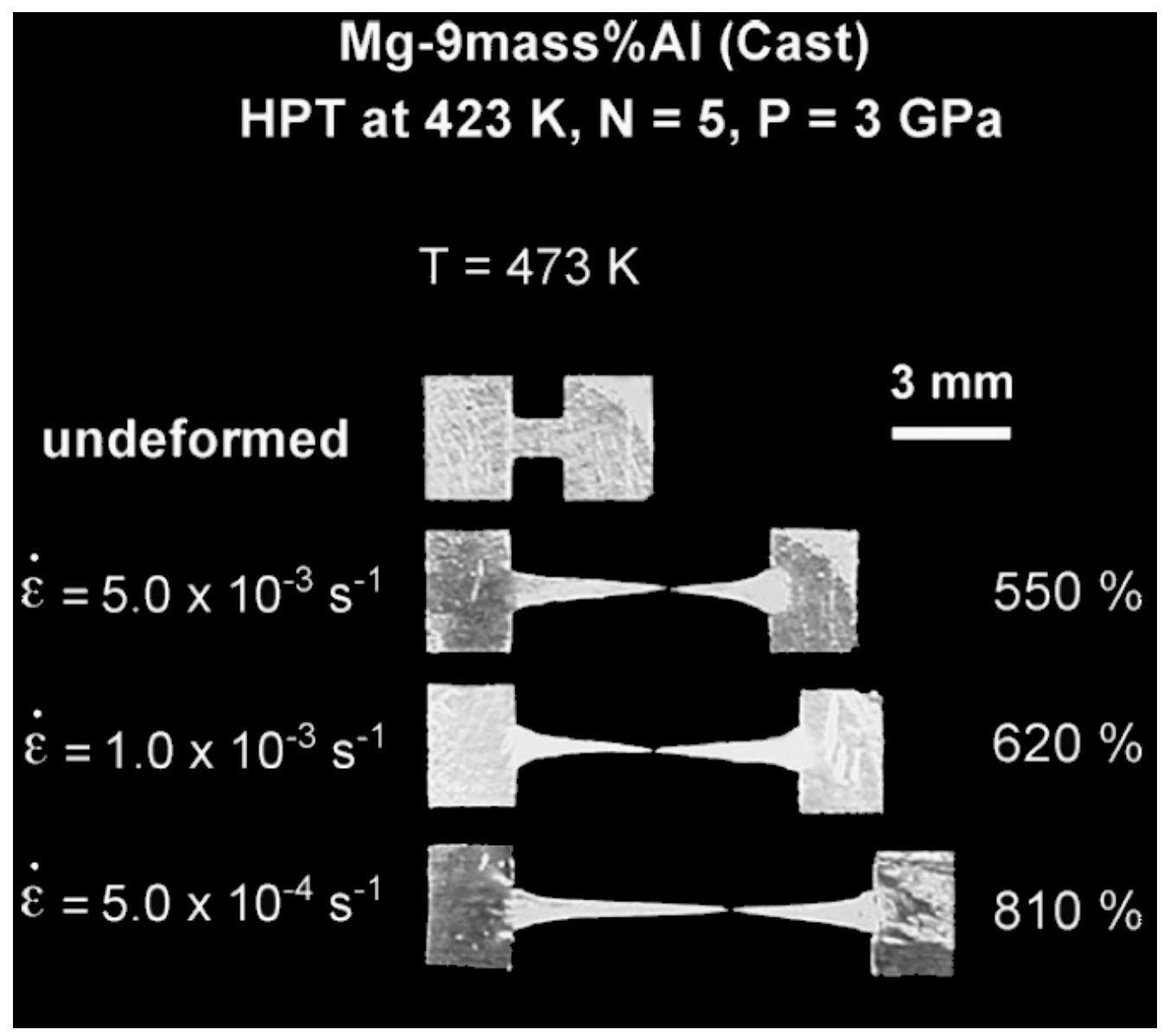

Figure 10 - Appearance of tensile specimens of a Mg-9\% Al alloy processed by HPT and pulled to failure at $473 \mathrm{~K}$ at different strain rates. Reproduced with permission. ${ }^{[65]}$ Copyright 2008, Elsevier. 


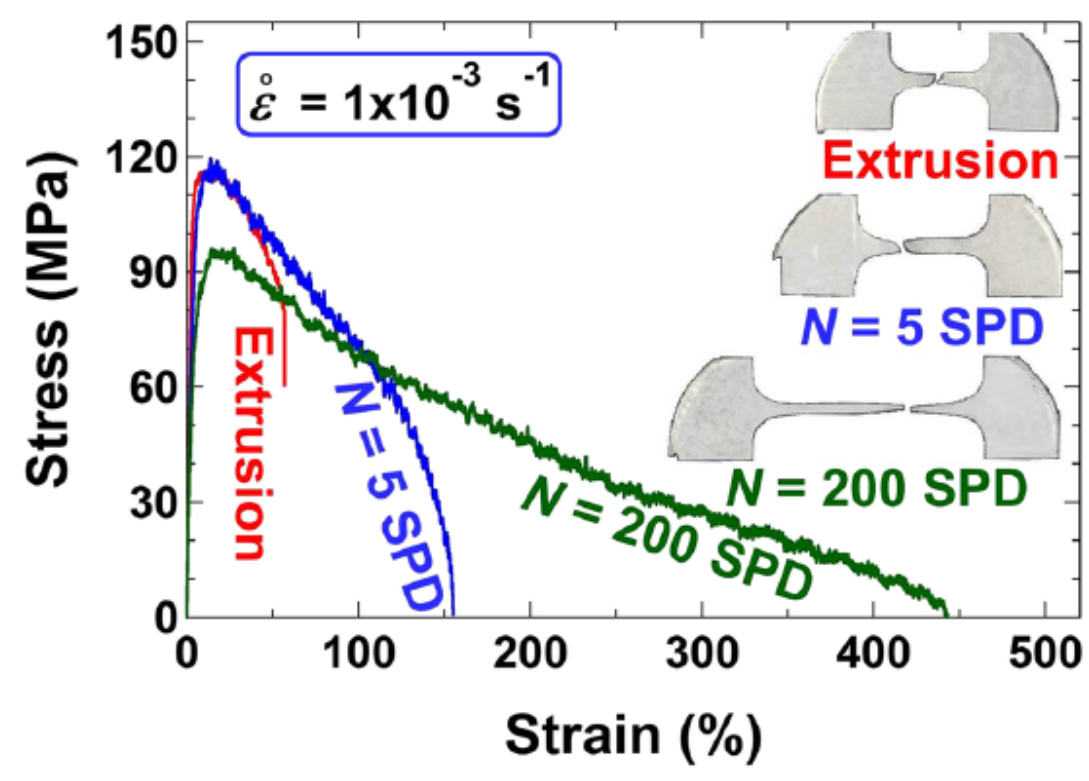

Figure 11 - Stress vs strain curves for Mg-Li alloy processed by HPT and tested in tension at room temperature. Reproduced under CC-BY 4.0 license. ${ }^{[89]}$ Copyright 2018, Springer Nature Limited. 


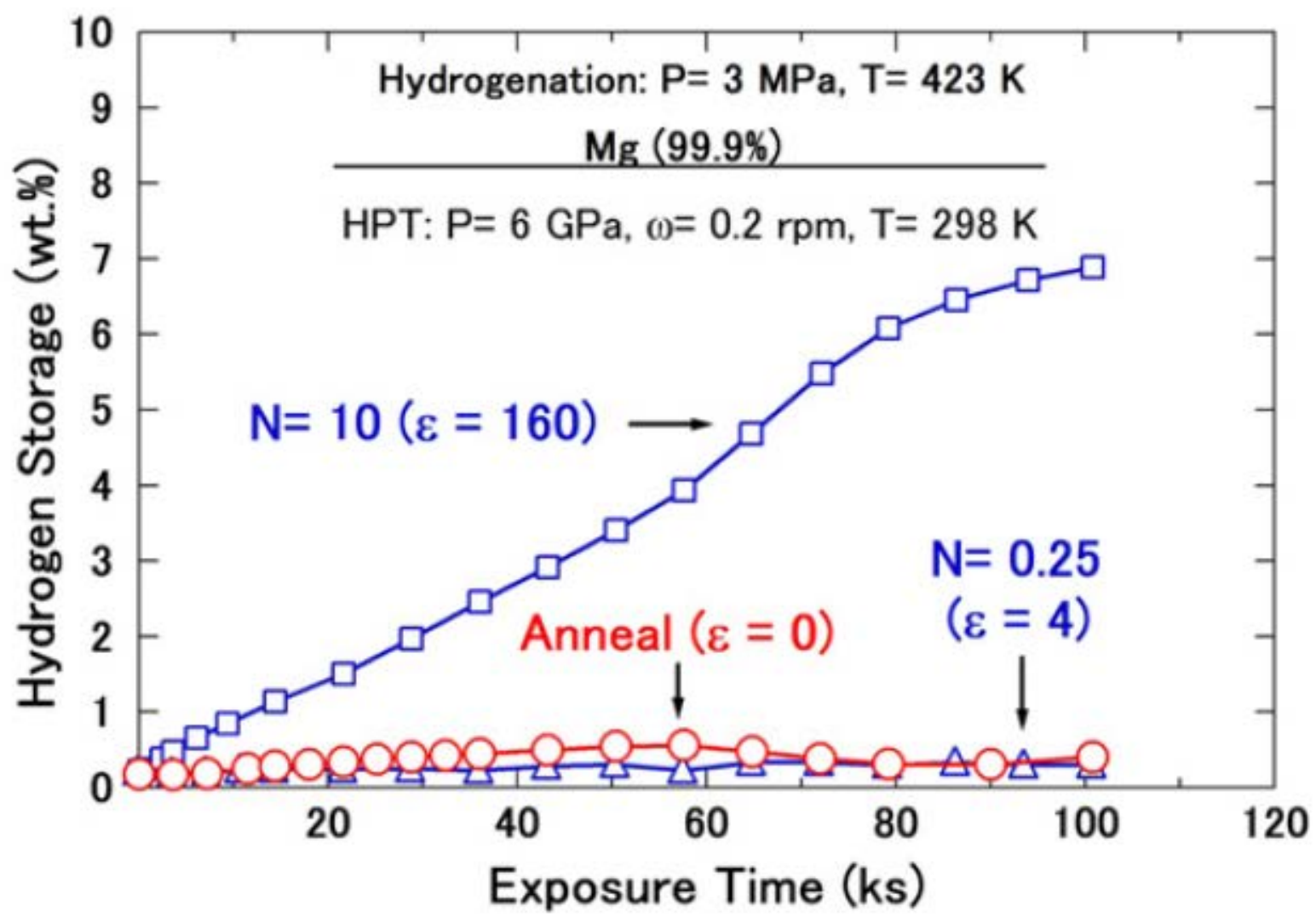

Figure 12 - Hydrogen storage as a function of exposure time for pure magnesium in the annealed condition and after HPT processing. Reproduced with permission. ${ }^{[51]}$ Copyright 2011, Elsevier. 


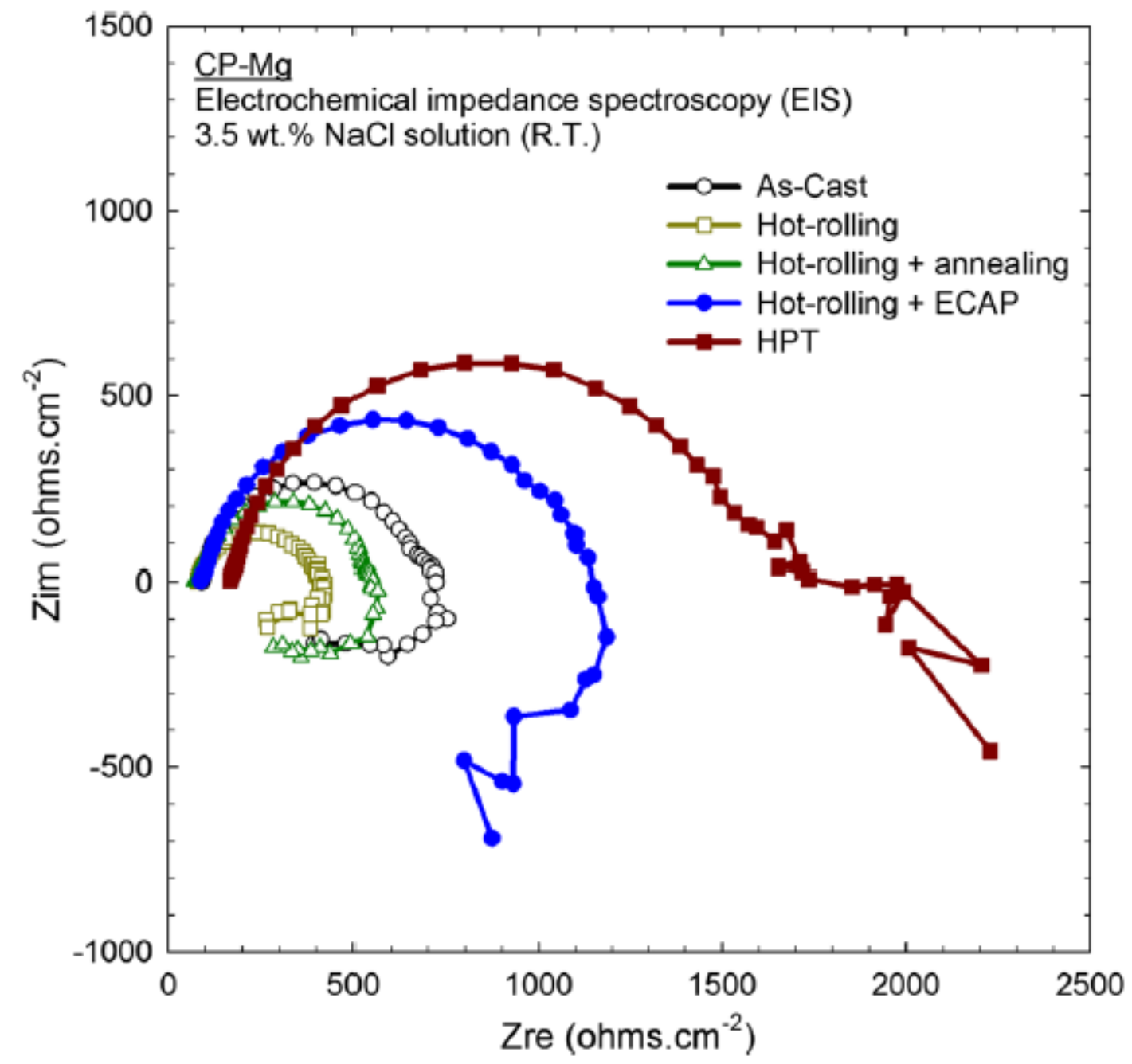

Figure 13 - Nyquist curves determined in $\mathrm{NaCl}$ solution for magnesium with different processing histories. Reproduced with permission. ${ }^{[103]}$ Copyright 2017, Springer Nature. 


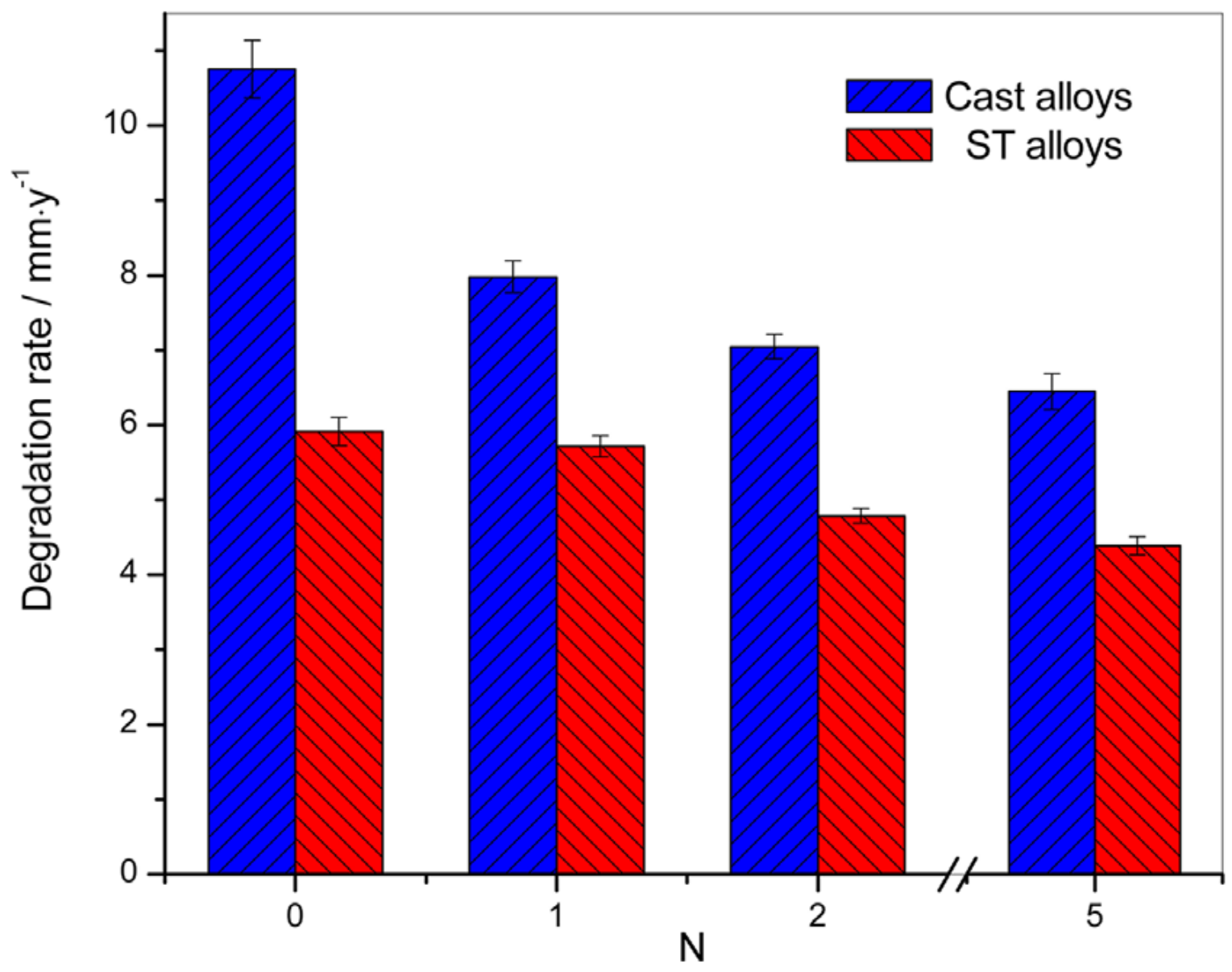

Figure 14 - Corrosion rate in Mg-Zn-Ca alloy processed by different number of turns of HPT in simulated body fluid. Reproduced with permission. ${ }^{[107]}$ Copyright 2016, John Wiley and Sons. 

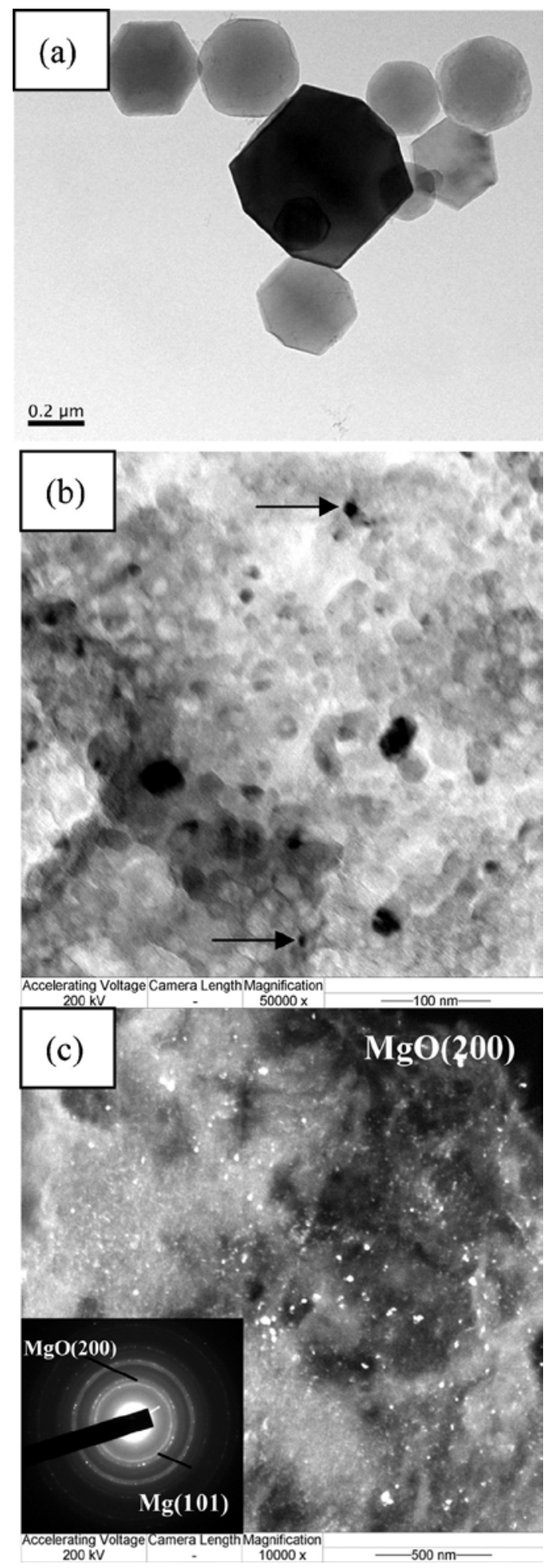

Figure 15 - TEM images of (a) pure magnesium powder and (b) bright and (c) dark field images of the Mg-MgO composite fabricated by HPT. Reproduced with permission. ${ }^{[109]}$ Copyright 2014, Elsevier. 

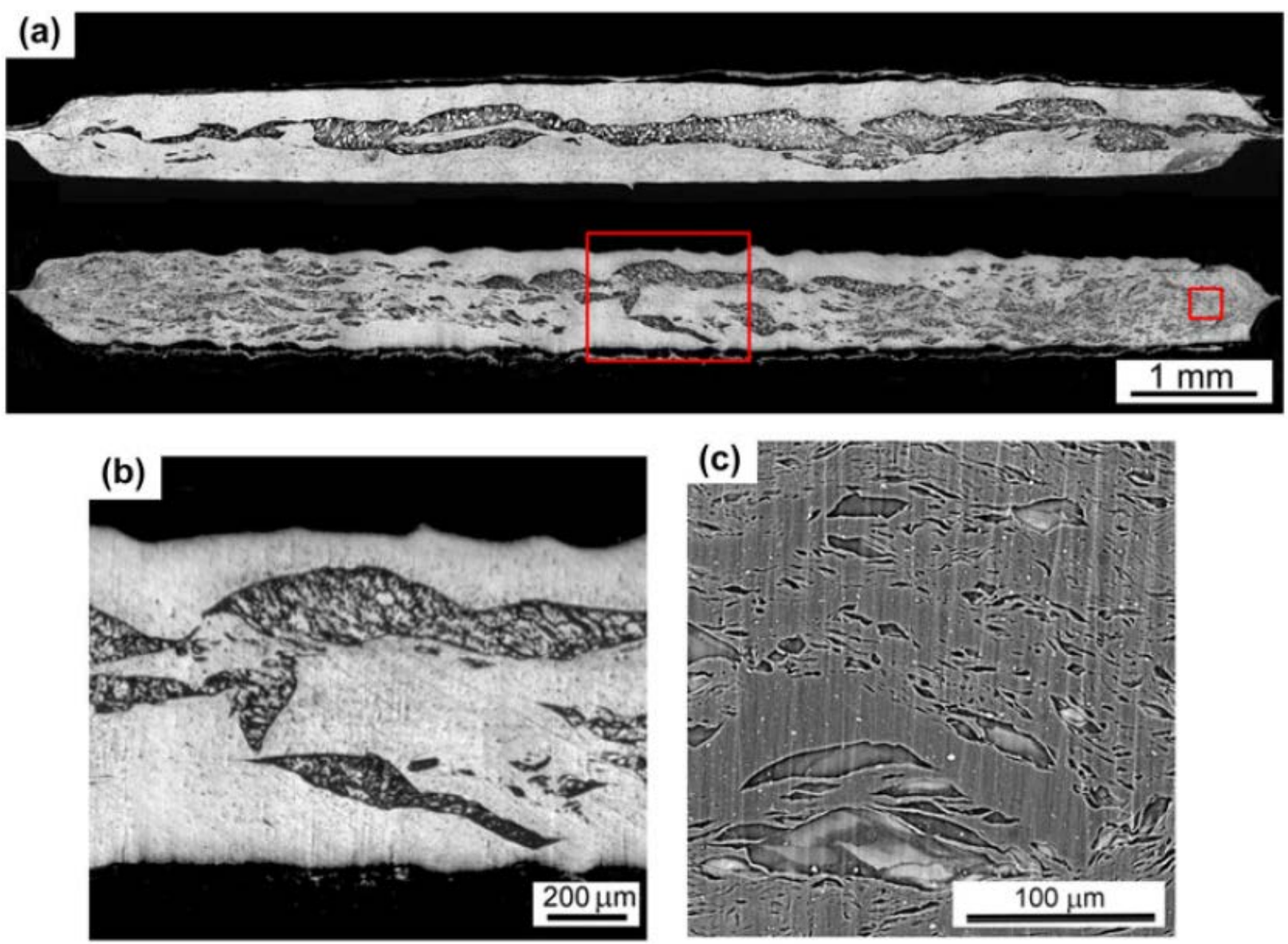

Figure 16 - (a) Appearance of the longitudinal section of an Al-Mg composite processed by 1 (upper) and 5 (lower) turns of HPT and higher magnification images of the structure at (b) the center and (c) at the edge of the disc processed by 5 turns. Reproduced with permission. ${ }^{[111]}$ Copyright 2015, Cambridge University Press. 